\title{
'You Will:' A Macroeconomic Analysis of Digital Advertising
}

\author{
Jeremy Greenwood, Yueyuan Ma, and Mehmet Yorukoglu*
}

\begin{abstract}
An information-based model is developed where traditional and digital advertising finance the provision of free media goods and affect price competition. Digital advertising is directed toward consumers while traditional advertising is undirected. The equilibrium is suboptimal. Media goods are under provided with both types of advertising. Additionally, traditional advertising is excessive because it is undirected. The tax-cum-subsidy policy that overcomes these inefficiencies is characterized. The model is calibrated to the U.S. economy. Digital advertising increases welfare significantly and is disproportionately financed by better-off consumers. The welfare gain from the optimal policy is much smaller than the gain from digital advertising.
\end{abstract}

Date: September 2022, revised

Keywords: AT\&T's "You Will" advertising campaign, consumer welfare, digital and traditional advertising, directed and undirected advertising, free media goods, GDP measurement, leisure, information frictions, price competition, public policy.

JEL Nos: E1, L1, O3.

${ }^{*}$ Greenwood, University of Pennsylvania; Ma, University of California, Santa Barbara; Yorukoglu, Koç University. You "Will" refers to AT\&T's 1994 advertising campaign. It introduced the first clickable ad. Comments are welcome! Address comments to Mehmet Yorukoglu at myorukoglu@ku.edu.tr 


\section{Opening}

\subsection{The Question}

The first clickable ad was on Hotwired.com in 1994, then the online version of Wired magazine-see Figure 1. It was part of AT\&T's "You will" campaign that prognosticated about the future in the information age. The ad enjoyed a click-through rate of 44 percent and cost AT\&T $\$ 30,000$ for three months. The digital advertising revolution had dawned. As with traditional advertising, digital advertising provides free media goods. It does so in spades. Think about Facebook, Google, Google Maps, Pandora, Twitter, Wikipedia, YouTube, and apps for dating, dieting, exercising, playing guitar, meditation, inter alia. Often these products are financed through advertising or the sale of marketing information for advertising purposes. Digital advertising has two benefits. First, it provides new forms of media goods. Second, it can be targeted better to consumers who might actually purchase the product. This increases the efficacy of advertising. As a result it spurs competition among firms resulting in lower prices. The benefits of digital advertising for the macroeconomy are not easily measured. Since media goods are not sold, they do not directly show up in the national income accounts but only factor in indirectly as an intermediate goods used to produce final consumption. Even if GDP is adjusted upwards to treat advertising as an intangible investment, GDP and welfare are not the same thing; think about the welfare benefit of vaccines versus their cost.

\section{Have you ever clicked your mouse right HERE? III}

Figure 1: The first clickable ad, part of AT\&T's "You Will" campaign. Source: The Atlantic, 2017.

How has the advent of digital advertising affected the macroeconomy? To address this question a modernized variant of Butters' (1977) information-based advertising model is used. New theoretical results are presented. Quantitative analysis of the prototype model is undertaken to illustrate its real world potential. The analysis is also used to explore numerically the properties of the model that can't be analyzed analytically. Since the prototype model's structure is simple, and the facts drawn upon to illuminate the framework are limited, this is somewhat an exercise in theory ahead of measurement. 
Significant hot rodding has to be done to bring Butters' (1977) framework up to speed for the task at hand. First, the framework is modified to allow for both digital and traditional advertising; Butter (1977) did not have such a distinction. Both types of advertising permit firms to convey information about products and prices to consumers, as in Butters (1977). Digital advertising is more efficient because it can be better directed toward consumers who can afford the products that firms are selling. Second, advertising is associated with the provision of free media-leisure goods, again something absent in Butters (1977). Third, unlike Butters (1977) ads are sold by advertising companies. The development of media-leisure goods incurs fixed costs, implying a scale economy. Such scale economies are thought to be important for advertising. This implies that the equilibrium quantity of media-leisure is not directly related to the amount of advertising done by firms. Fourth, to incorporate the free provision of media-leisure goods, and distinct from Butters (1977), a fully-fledged consumer sector is added. Consumers choose which varieties of goods to consume, based on the advertised prices they receive, and how much leisure to enjoy. Free media goods are taken to complement leisure in utility, in the sense of Edgeworth and Pareto. It is shown theoretically how an increase in the supply of free medialeisure goods will increase leisure, other things equal. This property is important for the subsequent calibration exercise. Fifth, consumers differ by their income, while in Butters (1977) they are all the same. Since consumers are different this allows digital advertising, which can be directed, to play an important role. It also allows for an assessment of who is implicitly paying for the cost of free media-leisure goods via the price markups reflecting advertising costs. Unlike Butters (1977), the maximum prices that consumers are willing to pay are endogenously determined as a function of the economic environment. These prices change as the economy evolves. A competitive equilibrium with both digital and traditional advertising is characterized. As in Butters (1977), a distribution of prices emerges for a product. This price distribution differs from Butters (1977) due to differences in consumers' incomes, the presence of both traditional and digital advertising, and the endogeneity of choke prices.

The resulting competitive equilibrium is not efficient, unlike Butters (1977), for two reasons. To start off with, free media goods are underprovided. Additionally, traditional adverts are sent to individuals who can't afford to buy the good at the advertised price. This wastes resources. The second-best tax-cum-subsidy policy that overcomes these inefficiencies in an informationally-constrained world with both types of advertising is fully characterized. Such a characterization is absent in the literature.

The developed model is calibrated using data on price markups, the ratio of 
advertising expenses to consumption expenditure, the ratio of spending on digital relative to traditional advertising, the college premium, and the time spent on media related leisure by non-college- and college-educated individuals. This is something Butters (1977) could not have done at the time of his research. The welfare gain from the introduction of digital advertising is computed. The increased provision of free media goods boosts consumer welfare significantly. It also leads to more leisure, since media goods and leisure are complements in utility. The increase in leisure is more pronounced for the non-college educated vis à vis the college educated. The gain in utility from the rise in leisure is largely offset by a decline in regular consumption because people earn less now.

The analysis suggests that affluent consumers may finance a disproportionately large share of the cost of media goods because they purchase goods at higher prices. These higher prices are due to higher markups from the cost of advertising. Yet, the move toward digital advertising may benefit affluent consumers more because it stimulates price competition at the higher price end of the goods market relative to the lower end. While implementing the second-best tax-cum-subsidy policy in an informational-constrained world increases welfare, the gain is fairly modest relative to the gain from the advent of digital advertising. Last, a comparison with the firstbest equilibrium without information frictions suggests that such frictions are fairly large.

\subsection{The Rise of Digital Advertising}

The composition of advertising spending changed as new vehicles for delivering ads cropped up, as Figure 2 shows. Ads in newspapers and magazines declined with the arrival of TV. Digital advertising rose with the advent of the information age. It's interesting to note that advertising's share of GDP has remained roughly constant in the postwar period at around 2 percent.

Online advertising is dominated by two giants, Facebook and Google. Google was founded in 1998 and Facebook in 2004. The ad revenue earned by these two companies (and Amazon) is shown in Figure 3 (right panel). Google's ad revenue shot up from around $\$ 70$ million in 2001 to $\$ 135$ billion in 2019 . Likewise, Facebook's ascent is equally dramatic, rising from roughly $\$ 2$ to $\$ 70$ billion between 2010 and 2019.

A breakdown of online advertising revenue by format is also displayed in Figure 3 (left panel). Online search is the dominant vehicle for digital advertising, followed by social media. Google inserts online ads into its products, such as Google Search, using a pay-per-click pricing model. The search advertising cost per click was $\$ 0.69$ 

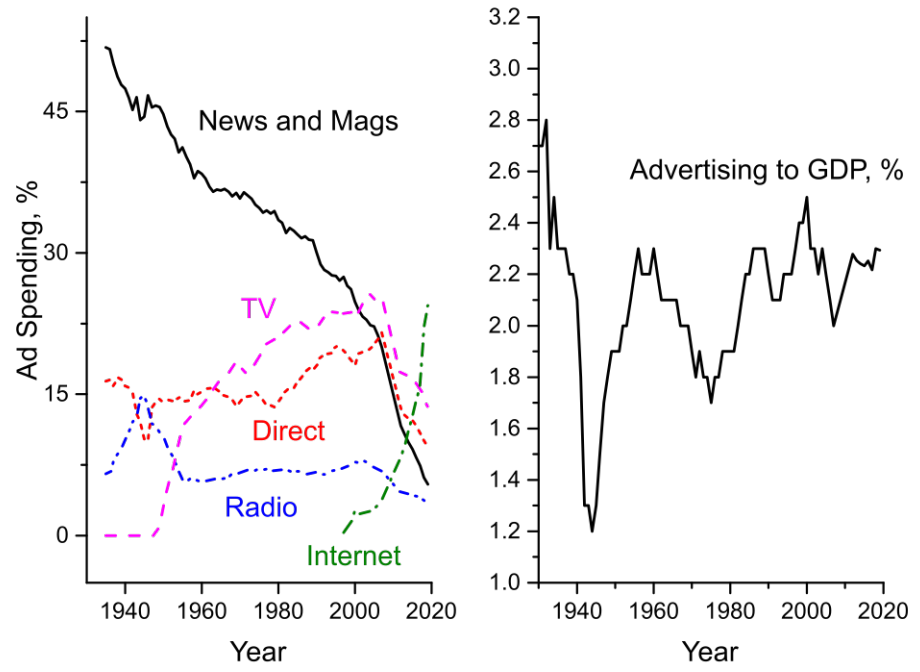

Figure 2: Advertising in the United States, 1935-2019. Advertising has consistently amounted to approximately 2 percent of GDP. Its composition has seen dramatic changes; however, as new mediums for communicating emerged. Sources: Douglas Galbi and AdAge.

in 2019. Google Search handled 5.4 billion search requests per day in 2019. Moving up from the third to the second position displayed by Google Search's results leads to a 31 percent increase in traffic. Advertisers pay for location. Apparently, only 0.78 percent of Google users make it to the second page of search results. The return on various mediums of advertising is presented in Figure 4, right panel. Digital search has the highest return in terms of sales per dollar spent on advertising. The left panel illustrates that spending by advertisers closely tracks the amount of time that consumers spend on the mediums.

A lot of digital content is provided for free via advertising. Think about the free goods just from Google: Chrome, Google Search, Google Maps, Gmail, Google Drive, YouTube, etc. Figure 5 shows the number of apps available in Google Play Store. In 2019 this was a whopping 2.8 million. Interestingly, consumers spend little for these products. Less than 14 percent of Google users spent more than $\$ 10$ for digital media in the Google Play Store, as the left panel illustrates. 

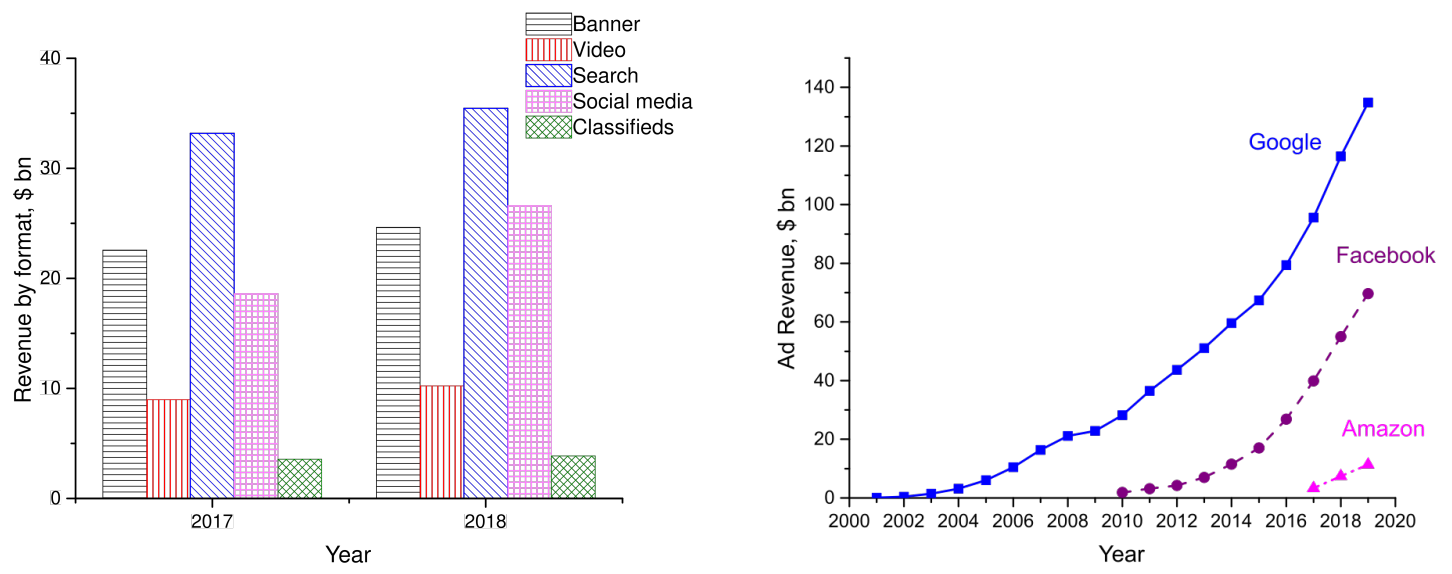

Figure 3: Right panel, ad revenue earned by Amazon, Facebook, and Google, 20012019. Left panel, distribution of U.S. online advertising revenue by format, 2017 and 2018. Source: statista.

\section{A Brief Review of the Advertising Literature}

Advertising has been part and parcel of economic life for a long period of time, as Figure 2 suggests. Until the second part of the twentieth century, however, economists paid little attention to advertising. The economic analysis of advertising can be traced back to insightful work by Marshall (1920). This subject area has flourished since then. ${ }^{1}$

At a time when competitive equilibrium and full information were the fundamentals of economic thinking, economists struggled with the question of why consumers would respond to advertising. Two views emerged. The first one holds that advertising is persuasive, altering consumers' tastes and creating brand loyalty. Not surprisingly, according to the persuasive view, advertising has no real value to consumers. It can have important anti-competitive effects, resulting in increased economic concentration. Marshall (1920, p. 304 and 306) noted that "much of the modern expenditure on advertising is not constructive, but combative," and that "advertisements which are mainly combative generally involve social waste."

The second view holds that advertising is informative, delivering information

\footnotetext{
${ }^{1}$ Bagwell (2007) provides a detailed survey of the literature, so only a capsule summary is given here. Given the coming of the information age, a lot has happened since then. See Anderson, Waldfogel, and Stromberg (2016) for literature reviews that capture the more recent advances associated with digital advertising.
} 

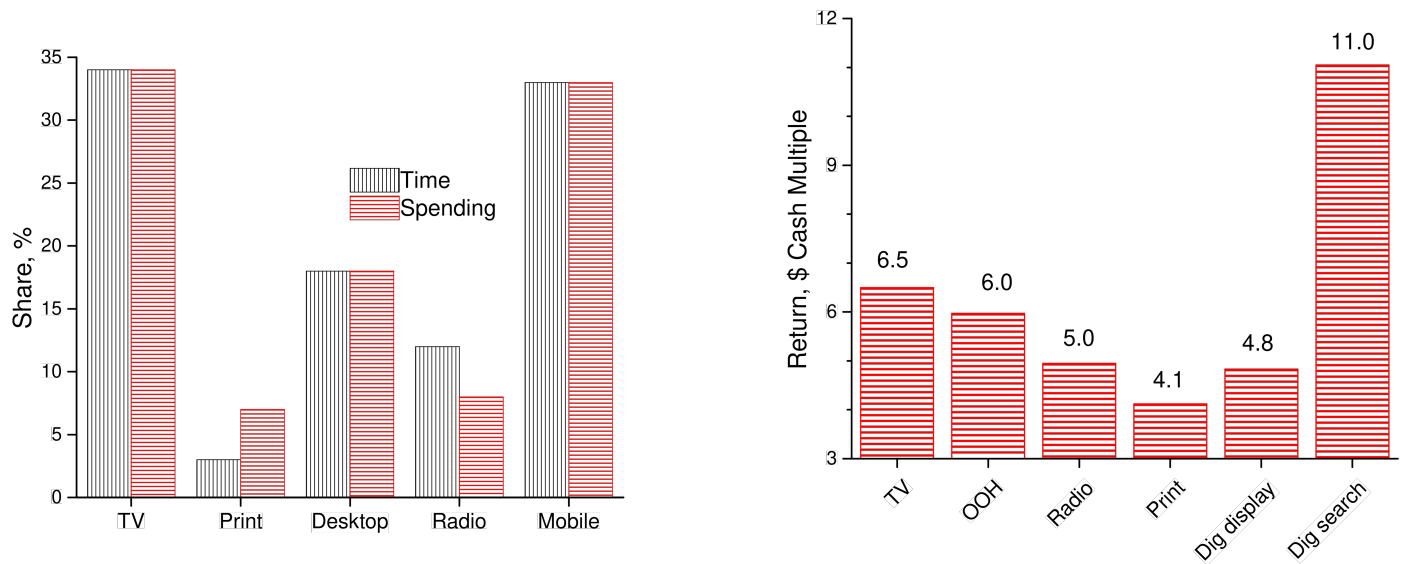

Figure 4: Right panel, the return per dollar of advertising by medium in the United States for 2017, measured as a cash multiple, 2001-2019. Left panel, U.S. advertising spending vs time spent by consumers by medium, 2018. Source: statista.

about prices. qualities, and new products. According to this perspective, markets are characterized by imperfect consumer information that leads to inefficiencies. Here, rather than being a problem, advertising emerges as a remedy offered by the market. Clearly, according to the informative view, advertising promotes competition. Marshall (1920, p. 305) also thought that advertising could be constructive by "the assistance, which they afford to customers by enabling them to satisfy their wants without inordinate fatigue or loss of time, would be appropriate, even if the business were not in strong rivalry with others." He noted that "exceptionally constructive are all those measures needed for explaining to people generally the claims of some new thing, which is capable of supplying a great but latent want." In the approach taken here advertising is informative. The foundation of the informative view of advertising was laid by Ozga (1960) and Stigler (1961). They saw price dispersion as a reflection of consumer ignorance and advertising as a valuable source of information for consumers that results in a reduction in price dispersion. Telser (1964) significantly advanced the theoretical and empirical foundations for the informative view, concluding that advertising is a sign of competition and is an important source of information for the consumers. Following these lines, Butters (1977) offered the first equilibrium analysis of advertising in a multi-firm model. He showed that advertising in equilibrium is efficient. Stegeman (1991) extended Butters' (1977) work with the assumption that consumers' valuations of products are heterogeneous. He 

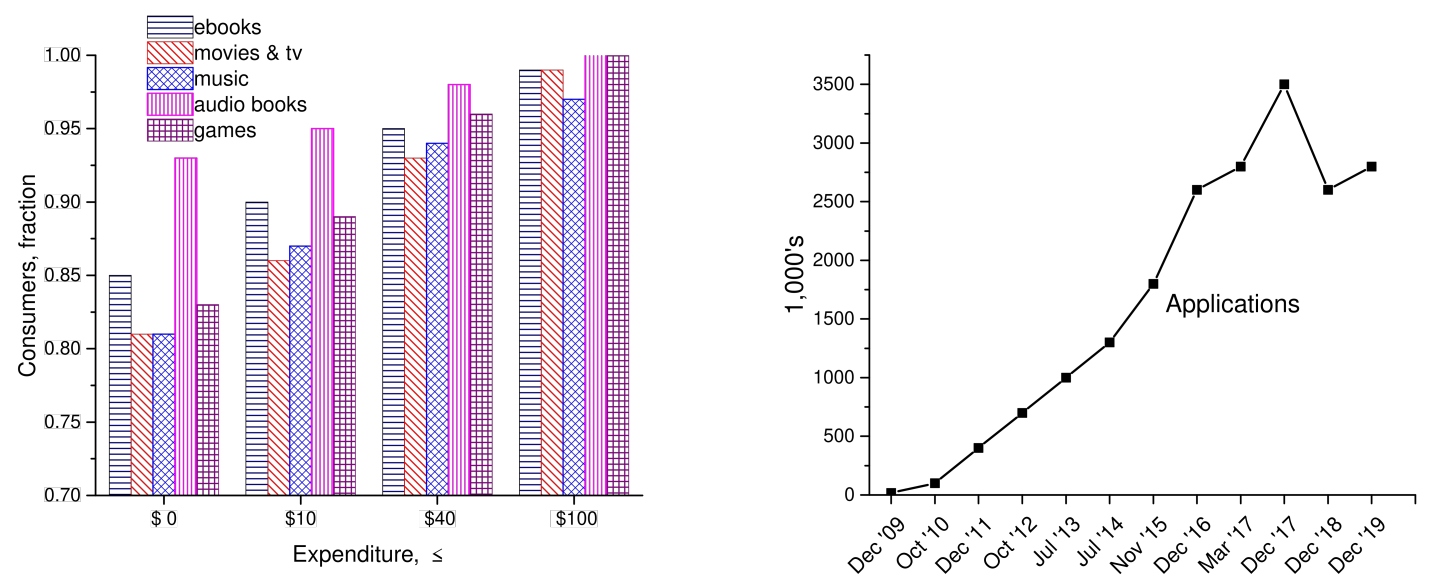

Figure 5: Right panel, applications in the Google Play Store, 2009-2019. Left panel, money spent by U.S. consumers on Google digital media products in 2017, presented in cumulative distribution form. Source: statista.

demonstrated that informative advertising is then inefficient. ${ }^{2}$

Extending Butters' (1977) model to an economy where firms have differing levels of productivity, Dinlersoz and Yorukoglu (2008) studied how improvements in advertising technology affect industry equilibrium. In related work, Dinlersoz and Yorukoglu (2012) analyzed how advertising technology affects firm dynamics. They showed that entry, exit, and volatility in firm size and value, increase as advertising technology improves. The equilibria in both models are efficient. Along the same lines, Gourio and Rudanko (2014) studied the role in firm and industry dynamics that the customer acquisition process has through marketing.

Incorporating advertising into macroeconomic frameworks is relatively new. In recent work, Perla (2019) builds a model where consumers learn about firms slowly through a network of connections between consumers and firms that endogenously evolves through the life cycle of an industry. The implications of advertising for

\footnotetext{
${ }^{2}$ Digital advertising was not around at the time of Stegeman's (1991) paper. Like Butters (1977), he did not have a fully fleshed-out consumer sector, which wasn't needed for their analyses. The latter is important for the current inquiry for three reasons. First, consumer behavior changes as the economy evolves due to technological progress in advertising. Second, the way media leisure goods enter tastes is important for consumption and leisure. Third, tastes need to be specified in order to undertake a welfare analysis. Additionally, Stegeman did not present the optimal taxcum-subsidy policy that renders the advertising economy efficient. Last, he did not take the model to data; calibration was in its infancy at the time of his research. Stegeman's is also a model of undirected advertising.
} 
firm dynamics and economic growth through its interaction with R\&D investment at the firm level are analyzed by Cavenaile and Roldan (2021) and Cavenaile et al. (2022). Cavenaile and Roldan (2021) provide empirical evidence supporting substitution between advertising and $\mathrm{R} \& \mathrm{D}$ using exogenous changes in the tax treatment of R\&D expenditures across U.S. states. Rachel (2019) argues that the rise of leisure goods provided by advertising has an adverse impact on welfare. As leisure rises the amount of labor going into R\&D declines. This stifles growth. Dinlersoz, Goldschlag, Yorukoglu, and Zolas (2021) incorporate the interaction between advertising and trademarks in a macroeconomic model to study the impact of trademarking on product quality, the reallocation of resources across firms, and welfare.

Cavenaile and Roldan (2019), Cavenaile et al. (2022), and Rachel (2019) take the persuasive approach to advertising, as opposed to the information-based one here. They use models of monopolistic competition. Advertising benefits firms by either influencing consumer tastes or as a direct input into production. Firms use advertising to get a leg up on a competitors. In a Nash equilibrium their competitors are doing exactly the same thing so advertising has the counterproductive element to it in the flavor of Marshall (1920). By contrast in the model developed here advertising is wasteful in the sense that some consumers are getting ads for products at high prices that they will never buy. Directed advertising mitigates this problem.

According to Goldfarb (2014) the fundamental difference between traditional and digital advertising is a substantial reduction in the cost of targeting when using the latter. In the information age advertisers collect vast amounts of information about potential customers. They can target the keywords customers use in search engines, demographic characteristics such as age, sex, location, etc, and a consumer's past online behavior. ${ }^{3}$ Models with representative consumers cannot tackle this question. The analysis here uses income heterogeneity to analyze the implications of targeting. The advertising-financed business model is captured in the literature by a two-sided market, as first proposed by Caillaud and Jullien (2001, 2003) and Rochet and Tirole (2003)-see Anderson, Waldfogel, and Stromberg (2016) for literature reviews. The basic idea is that the advertising platform serves a two-sided market where one side is firms, and the other side is consumers. The platform is a monopoly that maximizes its profit by choosing the number of ads it sells. In line with this notion, and different from Cavenaile and Roldan (2021) and Cavenaile et al. (2022), in the model developed here advertising is sold by ad agencies to firms. The free media goods developed by advertisers are the vehicle for distributing advertisements, The framework utilized deviates a bit from the classical model by assuming that the

\footnotetext{
${ }^{3}$ It is common for digital advertising agencies to buy bank account and credit card information from third parties. By analyzing the bought data, they know consumers' incomes (and savings.)
} 
platform (advertising agency) is perfectly competitive.

\section{Setup}

The analysis starts with the case of undirected traditional advertising (Sections 4 to 8), where firms cannot target individuals by their income levels. Here the bulk of machinery used in technical analysis is developed. It then turns to the case of directed digital advertising (Section 9), where firms can use information about income to target customers. After this, a hybrid model is presented with both types of advertising (Section 10). The hybrid model is calibrated to the U.S. data (Section 11). The impact of directed digital advertising on welfare is then addressed (Section $12)$.

Many features of the setup are shared by all three setting: the traditional, digital, and hybrid advertising models. ${ }^{4}$ These are discussed now. To this end, consider an economy with three types of goods; namely, generic consumption goods, medialeisure goods, and leisure. At most a unit measure of varieties of regular consumption goods can be produced. There is free entry into the production of each variety of regular goods, $u \in[0,1]$. Consequently, there are many firms producing each variety. To sell its product a firm must advertise to potential customers, which is costly. Advertising is purchased by firms from ad agencies. The ad contains information about the firm's product price. The cost of advertising is incorporated into the product price. A potential customer receives ads for a variety in a random manner. A producer of regular good $u$ is free to set the price, $p(u)$, that it wants. This can differ across variety- $u$ producers because consumers will vary in the advertised prices that they randomly received in their information sets. For each variety they may receive an ad from many of the producers or they may receive no ads at all.

Ad agencies sell advertising campaigns. They deliver ads, containing price information, via media-leisure goods that are provided to consumers for free. There are $\mathfrak{m}$ free media-leisure goods available, which will be endogenously determined. Advertising can be done in two ways. The first way is through traditional advertising,

\footnotetext{
${ }^{4}$ The setup is static. Adding dynamics would greatly complicate things-see for instance Dinlersoz, Goldschlag, Yorukoglu, and Zolas (2021). Clean theoretical results would be difficult to obtain. The static setup is not much of a drawback for the question at hand, however, since issues such as the entry of new products and growth are abstracted from. For new products the buildup of information over time might be important. The rise of digital advertising has been very rapid, implying that any transitional dynamics would need to operate at a fast clip. Also, the depreciation rate on advertising is high, somewhere between 30 and 50 percent, so treating it as a flow rather than a stock is not a great violation for the question entertained here.
} 
which is undirected. The second is via modern directed digital advertising.

\subsection{The Consumer/Worker}

Turn now to the consumer/worker. Regular good- $u$ must be consumed in the discrete quantity $c(u) \in\{0,1\}$. An individual might not consume the full spectrum of regular goods because either they didn't receive an ad for a good or because they couldn't afford them at the advertised price. Since media-leisure goods are free, the consumer enjoys the full spectrum of what is available, $\mathfrak{m}$. There is a unit mass of people, divided between the non-college educated and the college educated. These two education types will be subscripted when needed by $i=n, c$. The fractions of the population who are non-college and college educated are denoted by $\mathfrak{t}$ and $1-\mathfrak{t}$. The productivity levels for non-college- and college-educated-workers are given by $\pi_{n}$ and $\pi_{c}$, where $\pi_{n}=1<\pi_{c}$. A person who is non-college educated earns the wage rate $\pi_{n}=1$. A college-educated person, $\pi=\pi_{c}$, earns the wage $\pi_{c}$, but must incur a fixed education cost, $\mathfrak{e}$, in terms of time. In the equilibrium modeled, a college-educated person will have a higher level of income than a non-college-educated person. The wage rate for non-college labor is the numeraire, which implies that all goods prices are measured in terms of non-college labor. An individual has one unit of time that they can split between working in the market, $h$, leisure, $l$, and education, $\mathfrak{e}$. As will be seen in Section 6 on the consumer/worker's choice problem, the education cost helps to ensure that the college educated work more than the non-college educated, since the former must recover their investment in human capital.

Preferences are given by

$$
\theta \ln \left[\int_{0}^{v} c(u) d u\right]+\frac{(1-\theta)}{\rho} \ln \left[\kappa l^{\rho}+(1-\kappa) \mathfrak{m}^{\rho}\right], \text { with } \rho<0,
$$

where $v \leq 1$ demarcates the set of available regular goods and $\mathfrak{m}$ represents the quantity of free media goods. The set of available regular goods is endogenously determined in equilibrium. The quantity of free media goods is exogenous from the consumer's perspective. It will be endogenously determined by the amount of advertising in the economy, which is a function of the number of firms selling regular goods (and hence advertising). These preferences are well defined even when particular varieties of consumption goods are not consumed. Media goods can be mixed with leisure to generate utility; i.e., they are leisure goods. For example, you must spent time to enjoy an online game. The fact that regular consumption goods are aggregated linearly is not an undue restriction. Consumption within a variety is 
indivisible and hence there is no intensive margin of consumption. The consumer decides whether or not to consume an extra variety, which is a continuous decision. Total consumption for a person moves smoothly as in the standard macroeconomic model.

The assumption that $\rho<0$ implies that leisure, $l$, and media-leisure goods, $\mathfrak{m}$, are Edgeworth-Pareto complements in utility-in other words, the cross partial in utility is positive. The idea is that more media-leisure goods increase the marginal utility of leisure. Therefore, you want more leisure at the margin. The notion of leisure complementing goods is in Greenwood and Vandenbrouke (2008) and Kopecky (2011). Kopecky (2011) suggests the decline in the price of leisure goods encouraged the elderly to spend a larger fraction of their life in retirement. Aguiar et al. (2021) use this notion to argue that part of the recent decline in hours worked by young males is due to the advent of recreational computing. Kopytov et al. (2021) find that declining recreation good prices can account for much of the increase in leisure in both the United States and across the world, due to their complementarity with leisure.

Last, the individual's budget constraint is given by

$$
\int_{0}^{v} p(u) c(u) d u=\pi_{i} h_{i} \equiv \begin{cases}\pi_{c}(1-l-\mathfrak{e}), & \text { college } \\ 1-l, & \text { noncollege }\end{cases}
$$

where, with some abuse of notation, in this context $p(u)$ represents the minimum price for good $u$ that the consumer/worker has in their information set and $h_{i}$ is the hours worked by a type- $i$ person for $i=n$ (non-college) and $i=c$ (college).

\subsection{Final Goods Producers}

Firms can freely enter into the production of any variety of regular goods. Firms choose the price for their product and the scale of the advertising campaign that they purchase from ad agencies. The scale of the firm's advertising campaign will determine its sales, and hence profits. If there are $v$ active varieties of goods with $n$ firms producing each variety, then there is a total of $v n$ firms in the economy. The quantities $v$ and $n$ will be determined in equilibrium by the fact that firms must earn zero profits. Any variety of regular goods can be produced by a firm according to the constant-returns-to-scale production

$$
o=\mathbf{h} / \gamma
$$


where $o$ is the output of the good and $\mathbf{h}$ is the amount of labor employed. The unit time cost (in terms of non-college labor) of producing a good is $\gamma$.

To sell its product at time price $p$, a firm must reach out to customers, which involves advertising. ${ }^{5}$ The firm employs ad agencies for its advertising campaigns. The cost of a traditional marketing campaign that disseminates $a_{t}$ ads is $T\left(a_{t}\right)$. Expanding the scale of the campaign to reach everyone is increasingly difficult so that $T_{1}\left(a_{t}\right)>0$ and $T_{11}\left(a_{t}\right)>0$. The properties of this function are discussed in the next section. Likewise, the cost of a digital marketing campaign is $D\left(a_{d}\right)$, with similar properties, and where $a_{d}$ is the number of digital ads.

\subsection{Ad Agencies}

Advertising is sold by ad agencies to firms. The ads for each firm's advertising campaign are delivered through a media good, which can be either a traditional or digital conduit. The sizes of traditional and digital media goods, $\mathfrak{m}_{t}$ or $\mathfrak{m}_{d}$, are fixed and will be calibrated in Section 11. There is a fixed cost for providing the media good associated with an advertising campaign. Let this cost be $\mathfrak{r}$ for an advertising campaign (where the cost is in units of non-college labor). There is also a variable cost connected with the scale of the campaign. The variable cost (measured in terms of non-college labor) for traditional advertising is

$$
A\left(a_{t}\right)=\phi a_{t}^{\alpha}, \text { with } \alpha>1
$$

Think about $a_{t}$ as representing the quantity of ads received and viewed by consumers. Doubling the number of ads will not double the amount of views. Reaching some consumers is more difficult than others and consumers have limited attention spans. Therefore, although the media goods provided by the ad agencies are enjoyed by all and are developed at a fixed cost, the number of successful ads that receive potential customers' attention has diminishing returns. Therefore, the production cost of a

\footnotetext{
${ }^{5}$ This is a key distinction between a Butters-style advertising model and a directed search model. In a directed search model there is no friction associated with providing consumers information about posted prices. Additionally, unlike a directed search model, in an advertising model a firm can supply all customers who want to buy its product. In a directed search model customers queue up to buy a product from a firm with limited selling capacity. Thus, a customer can only expect to purchase the good with some probability. So, the friction here concerns the prices that consumers have in their information sets and not whether a consumer will be able to buy a good from the firm at the posted price.
} 
traditional advertising campaign is

$$
\mathfrak{r}+A\left(a_{t}\right)
$$

If there is free entry into the advertising business, then the price of a traditional advertising campaign of size $a_{t}$ is

$$
T\left(a_{t}\right)=\mathfrak{r}+A\left(a_{t}\right)
$$

In equilibrium there will be many ad agencies operating. As can be seen, the advertising campaign sold to a firm has both an increasing and decreasing returns to scale aspect.

Likewise, suppose that the fixed cost of producing digital media goods is $\mathfrak{r}$ and that the variable cost of producing $a_{d}$ digital ads is

$$
A\left(a_{d}\right)=\phi a_{d}^{\alpha}
$$

There is no cost advantage to digital advertising. Importantly, if digital advertising can be directed to consumers who possibly will buy the product, then this does offer an advantage over traditional advertising-directed advertising is turned to in Section 9. The price of a digital advertising campaign of scale $a_{d}$ is

$$
D\left(a_{d}\right)=\mathfrak{r}+A\left(a_{d}\right)
$$

\section{Traditional Advertising}

The analysis starts with traditional advertising that cannot be directed to consumers based on their income. Digital advertising, which can be directed, is introduced in Section 9. Consumers will differ in the ads that they have in their information sets for a particular variety. Therefore, firms do not have to charge the same price. The generic distribution of ads over all varieties will be identical across consumers, as will be discussed when presenting the consumer/worker problem in Section 6. This information friction allows a firm to charge a price higher than its marginal production cost, $\gamma$. Still, all firms will make zero profits after paying for their ad campaigns.

Let $\underline{p}$ represent the lowest profitable price in equilibrium and likewise $p_{c}$ denote the maximum profitable one. Only the college educated will make a purchase at the highest price, $p_{c}$. Now, a firm is free to charge any price $p$ such that $\underline{p} \leq p \leq p_{c}$. 
The higher the price, the less likely the firm will make a sale, because it becomes more likely that a consumer will have received an ad for another firm selling the same product at a lower price. The set of viable equilibrium prices, $\mathcal{P}$, is characterized later in Proposition 2. Since there is free entry into a variety, it must transpire that a firm will earn the same profit at any price, $p \in \mathcal{P}$.

Let $S(p)=\operatorname{Pr}(\operatorname{SALE} \mid p)$ be the probability that an ad at price $p$ will generate a sale for the firm. This probability is exogenous for a firm and is unpacked later. The firm chooses its traditional advertising strategy to maximize its profits at price $p$. So, its advertisements solve

$$
\Pi(p) \equiv \max _{a_{t}}\left\{(p-\gamma) a_{t} S(p)-T\left(a_{t}\right)\right\} .
$$

Here the term $p-\gamma$ represents the firm's unit profits (excluding advertising costs) while $a_{t} S(p)$ is the firm's total sales. Its advertising costs are $T\left(a_{t}\right)$. The firm takes into account how the scale of its ad campaign determines how much it must pay to the ad agency. The first-order conditions for $a_{t}$ is

$$
(p-\gamma) S(p)=T_{1}\left(a_{t}\right)
$$

The lefthand side of this expression is the expected profit (or marginal benefit) from sending out an extra ad. The righthand side represents the marginal cost of an extra traditional ad received by a customer.

Proposition 1. (Advertising) All firms do the same amount of traditional advertising, $a_{t}$, even when charging different prices for their products, $p \in \mathcal{P}$.

Proof. See Appendix A.

Remark. This implies that all ad agencies operate at the same scale.

To understand the logic underlying the proposition, note that in equilibrium a firm is free to pick any price it desires. So, expected unit profits, $(p-\gamma) S(p)$, must be constant across equilibrium prices. Suppose not. Then firms with higher values for $(p-\gamma) S(p)$ would make more than firms with lower values because the former could always do the same amount of advertising as the latter.

If the marginal benefit is constant across prices, then from (6) so must be the marginal costs. This implies that marginal cost is invariant across prices, $p$. From (3) it transpires that

$$
T_{1}\left(a_{t}\right)=\phi \alpha a_{t}^{\alpha-1} .
$$


Inserting this expression into (6) yields

$$
a_{t}=\left[\frac{(p-\gamma) S(p)}{\alpha \phi}\right]^{1 /(\alpha-1)}
$$

or equivalently

$$
a_{t}=\left[\frac{(\underline{p}-\gamma) S(\underline{p})}{\alpha \phi}\right]^{1 /(\alpha-1)} .
$$

where the second line follows from the proposition. If there are $n_{t}$ firms producing each variety, then the total number of adverts per variety, $a$, is

$$
a=n_{t} a_{t}=n_{t}\left[\frac{(\underline{p}-\gamma) S(\underline{p})}{\alpha \phi}\right]^{1 /(\alpha-1)} .
$$

\section{$5 \quad$ Pricing with Traditional Advertising}

\subsection{Advertised Price Distribution}

Consumers receive ads randomly without any targeting by firms. Assume that there is a much larger mass of consumers vis à vis firms and that no consumer receives more than one ad from the same firm. Let $a$ represent the number of ads for a variety per consumer in the economy. The number of ads, $k$, that a consumer receives will be distributed according to a Poisson distribution $e^{-a} a^{k} / k ! .{ }^{6}$ Now, let $P(p)=\operatorname{Pr}(\mathrm{PRICE}$ $\leq p$ ) be the fraction of ads for a variety that have a price less than or equal to $p$. The distribution function for advertised prices, $P(p)$, is characterized later in Proposition

\footnotetext{
${ }^{6}$ To see this, imagine an economy with a discrete number of consumers, $\mathfrak{c}$, who are flooded with $a \mathfrak{c}$ ads per variety. The probability that a consumer will receive $k$ ads for a variety is distributed according to the binomial distribution

$$
\left(\begin{array}{c}
a \mathfrak{c} \\
k
\end{array}\right)\left(\frac{1}{\mathfrak{c}}\right)^{k}\left(1-\frac{1}{\mathfrak{c}}\right)^{a \mathfrak{c}-k},
$$

where $1 / \mathfrak{c}$ is the chance that a consumer gets an ad (success) and $1-1 / \mathfrak{c}$ are the odds that they won't (failure). Out of a set of $a \mathfrak{c}$ ads there are $\left(\begin{array}{c}a \mathfrak{c} \\ k\end{array}\right)$ ways each event could happen. Finally,

$$
\lim _{\mathfrak{c} \rightarrow \infty}\left(\begin{array}{c}
a \mathfrak{c} \\
k
\end{array}\right)\left(\frac{1}{\mathfrak{c}}\right)^{k}\left(1-\frac{1}{\mathfrak{c}}\right)^{a \mathfrak{c}-k}=e^{-a} a^{k} / k ! .
$$
}


3.

Three prices play a central role in the analysis; namely, the minimum price in the economy, $\underline{p}$, the maximum price at which the non-college educated will buy, $p_{n}$, and the maximum price at which the college educated will purchase, $p_{c} \geq p_{n}$. The minimum price is determined by technological considerations while the maximum prices also depend upon the outcome of the consumer problems for the non-college and college educated, an important distinction from Butters (1977). The consumer problems are presented in Section 6. Now, suppose a firm sends an ad to a consumer offering to sell the good at price $p$. The odds of a consumer with $k$ other ads having no price lower than $p$ are $[1-P(p)]^{k}$. Even when the firm's price $p$ is the lowest one in the consumer's information set, the person may not buy the good because it is too expensive. Let $I_{i}(p)=1$, for $i=n, c$, denote the situation when a type- $i$ consumer buys the firm's good at price $p$ and $I_{i}(p)=0$ when not. It then follows that the probability of an ad with price $p$ to a consumer will generate a sale, given that the consumer may have received $k=0,1,2, \cdots$ other ads, is given by ${ }^{7}$

$$
\begin{aligned}
S(p)=\operatorname{Pr}(\operatorname{Sale} \mid p)=e^{-a} \sum_{k=0}^{\infty} \frac{a^{k}}{k !}[1-P(p)]^{k}\left[\mathfrak{t} I_{n}(p)\right. & \left.+(1-\mathfrak{t}) I_{c}(p)\right] \\
& =e^{-a P(a)}\left[\mathfrak{t} I_{n}(p)+(1-\mathfrak{t}) I_{c}(p)\right] .
\end{aligned}
$$

The determination of $\underline{p}$ and $p_{c}$ is discussed now with the specification of $p_{n}$ following shortly after. Consider a firm that chooses to charge the minimum price, $\underline{p}$. All the ads that this firm sends out will result in purchases by consumers, implying $S(p)=1$. Since there is free entry into the production of any variety, this firm will earn zero profits. Hence,

$$
\Pi(\underline{p})=0
$$

Solving this equation gives

$$
\underline{p}=\left[\frac{\mathfrak{r}}{\Upsilon}\right]^{(\alpha-1) / \alpha}+\gamma
$$

where

$$
\Upsilon \equiv \phi^{1 /(1-\alpha)}\left(\alpha^{1 /(1-\alpha)}-\alpha^{\alpha /(1-\alpha)}\right)=\left(\frac{1}{\phi}\right)^{1 /(\alpha-1)}\left(\frac{1}{\alpha}\right)^{\alpha /(\alpha-1)}(\alpha-1)>0 .
$$

\footnotetext{
${ }^{7}$ To go from the first to the second line, set $s=\sum_{k=0}^{\infty}\left(a^{k} / k !\right) x^{k}=\left[1+a x+(a x)^{2} / 2 !+(a x)^{3} / 3 !+\right.$ $\cdots]$, which implies that $d s / d x=\left[a+a^{2}(a x)+a^{3}(a x)+\cdots\right]=a s$. Therefore, $(1 / s) d s / d x=a$ so that $s=e^{a x}$. Now, let $x=1-P(p)$ to get $\sum_{k=0}^{\infty}\left(a^{k} / k !\right)[1-P(p)]^{k}=e^{a[1-P(p)]}$, from which the desired result follows.
} 
(See the proof of Proposition 1 in Appendix A for guidance.) The minimum price, $p$, is determined solely by technological factors. As a consequence so is the amount of traditional advertising, $a_{t}$, that each firm does, a fact that follows from (9) in conjunction with $S(\underline{p})=1$.

Since a firm is free to pick any price, it must be the case that

$$
\Pi\left(p^{\prime}\right)=\Pi\left(p^{\prime \prime}\right) \text {, for any } p^{\prime} \text { and } p^{\prime \prime} \in \mathcal{P} \text {. }
$$

Proposition 1 states that all firms do the same amount of advertising. Therefore,

$$
\left(p^{\prime}-\gamma\right) S\left(p^{\prime}\right)=\left(p^{\prime \prime}-\gamma\right) S\left(p^{\prime \prime}\right)
$$

or equivalently

$$
\begin{aligned}
\left(p^{\prime}-\gamma\right) e^{-a P\left(p^{\prime}\right)}\left[\mathfrak{t} I_{n}\left(p^{\prime}\right)+(1-\mathfrak{t}) I_{c}\left(p^{\prime}\right)\right] & \\
= & \left(p^{\prime \prime}-\gamma\right) e^{-a P\left(p^{\prime \prime}\right)}\left[\mathfrak{t} I_{n}\left(p^{\prime \prime}\right)+(1-\mathfrak{t}) I_{c}\left(p^{\prime \prime}\right)\right] .
\end{aligned}
$$

Turn to the firm that charges the highest price, $p_{c}$. Only college-educated consumers $(i=c)$ who have no other ads will buy the firm's product. Therefore, $S\left(p_{c}\right)=e^{-a}(1-\mathfrak{t})$, because $P\left(p_{c}\right)=1$ (i.e., all ads have a price lower than $p_{c}$ ). Therefore, evaluating the above expression at $p^{\prime}=p_{c}$ and $p^{\prime \prime}=\underline{p}$ gives

$$
e^{-a}(1-\mathfrak{t})\left(p_{c}-\gamma\right)=\underline{p}-\gamma
$$

so that the maximum price at which a college-educated person buys a good is

$$
p_{c}=\frac{\underline{p}-\gamma}{e^{-a}(1-\mathfrak{t})}+\gamma=\frac{[\mathfrak{r} / \Upsilon]^{(\alpha-1) / \alpha}}{e^{-a}(1-\mathfrak{t})}+\gamma
$$

Next, focus on the highest price that non-college-educated consumers can afford, $p_{n}$. At any higher price there will be a discrete drop off in potential customers from 1 down to $1-\mathfrak{t}$. To recover profits there must be a discrete jump up in the lowest price above $p_{n}$, denoted by $p_{\uparrow n}$. Since there are no prices between $p_{n}$ and $p_{\uparrow n}$ it transpires that $P\left(p_{n}\right)=P\left(p_{\uparrow n}\right)$, which is formalized later in Proposition 3 . The prices at the left and righthand sides of the jump must have equal profits, so that 
$(1-\mathfrak{t})\left(p_{\uparrow n}-\gamma\right)=p_{n}-\gamma$, which yields

$$
p_{\uparrow n}=\frac{p_{n}-\gamma}{1-\mathfrak{t}}+\gamma
$$

Now, there must be firms charging every price, $p$, in the set $\mathcal{P}=\left[\underline{p}, p_{n}\right] \cup\left[p_{\uparrow n}, p_{c}\right]$. To understand why, suppose to the contrary that there is a hole in one of the intervals. Firms at the lower edge of the hole could increase profits by raising their price slightly, because this will not affect the number of customers they have. The proposition below describes the situation.

Proposition 2. (Pricing when Advertising is Undirected) For any variety of regular goods there are firms charging every price, $p$, in the set $\mathcal{P}=\left[\underline{p}, p_{n}\right] \cup\left[p_{\uparrow n}, p_{c}\right]$. Take the aggregate amount of advertising per variety, $a$, as given. Then, both $\underline{p}$ and $p_{c}$ are increasing in the fixed cost of advertising, $\mathfrak{r}$, and the marginal cost of production, $\gamma$. Last, the maximum price, $p_{c}$, is decreasing in the fraction of individuals, $1-\mathfrak{t}$, who are college educated.

Proof. See Appendix A.

It's probably obvious that an increase in the cost of doing business, as given by $\mathfrak{r}$ and $\gamma$, will lead to the pricing set $\mathcal{P}=\left[p, p_{n}\right] \cup\left[p_{\uparrow n}, p_{c}\right]$ shifting rightward, because given the free-entry assumption firms must recover their costs. When there are more college-educated consumers, $1-\mathfrak{t}$, it becomes more profitable to charge the maximum price, $p_{c}$, since the odds of an ad landing on a college-educated person increase. But, again, perfect competition will drive the maximum price down so that firms earn zero profits.

Direct attention now to characterizing the distribution of prices in the set $\mathcal{P}=$ $\left[\underline{p}, p_{n}\right] \cup\left[p_{\uparrow n}, p_{c}\right]$. Using the fact that $S(\underline{p})=1$ in equation (12) gives

$$
(p-\gamma) e^{-a P(p)}\left[\mathfrak{t} I_{n}(p)+(1-\mathfrak{t}) I_{c}(p)\right]=\underline{p}-\gamma, \text { for } p \in \mathcal{P}
$$

Since this equation must hold for all $p$ in the pricing set, $\mathcal{P}$, it traces out the distribution function for advertised prices, $P(p)$.

Proposition 3. (Advertised Price Distribution when Ads are Undirected) The cu- 
mulative distribution for advertised prices, $P(p)$, is given by

$$
P(p)=\operatorname{Pr}(\operatorname{PRICE} \leq p)= \begin{cases}\ln \{(p-\gamma) /(\underline{p}-\gamma)\} / a, & \text { for } p \in\left[\underline{p}, p_{n}\right] \\ \ln \left\{\left[p_{n}-\gamma\right] /(\underline{p}-\gamma)\right\} / a, & \text { for } p \in\left(p_{n}, p_{\uparrow n}\right) \\ \ln \{(1-\mathfrak{t})(p-\gamma) /(\underline{p}-\gamma)\} / a, & \text { for } p \in\left[p_{\uparrow n}, p_{c}\right]\end{cases}
$$

The associated density function reads

$$
P_{1}(p)= \begin{cases}1 /[a(p-\gamma)]>0, & \text { for } p \in\left[\underline{p}, p_{n}\right] \\ 0, & \text { for } p \in\left(p_{n}, p_{\uparrow n}\right) \\ 1 /[a(p-\gamma)]>0, & \text { for } p \in\left[p_{\uparrow n}, p_{c}\right]\end{cases}
$$

Proof. See Appendix A.

Figure 6 illustrates the cumulative distribution for prices. The distribution function for advertised prices (first-order) stochastically dominates the one for transacted prices. Consumers buy at the lowest price in their information set. For subsequent use note that $P_{1}(p)$ represents the fraction of ads offering to sell a variety at price $p$.

\subsection{Maximum Price the Non-College will Pay, $p_{n}$}

What is the maximum price, $p_{n}$, at which a non-college-educated person will buy a good? To begin with, since $S(p)=1$, equation (12) also implies

$$
S(p)=\frac{(\underline{p}-\gamma)}{(p-\gamma)}, \text { for } p \in \mathcal{P}
$$

Let $B(p)=\operatorname{Pr}(\mathrm{BUY})$ represent that the probability that a consumer will buy at price $p$. This is not quite the same as the probability that a firm will make a sale at price $p, S(p)$, because the latter averages over both types of consumers. The two probabilities are related as follows:

$$
B(p) \equiv \operatorname{Pr}(\mathrm{BUY})= \begin{cases}S(p), & \text { for } p \in\left[\underline{p}, p_{n}\right] \\ S(p) /(1-\mathfrak{t}), & \text { for } p \in\left[p_{\uparrow n}, p_{c}\right]\end{cases}
$$

For a given variety, the odds of a purchase at price $p$ by a consumer are $P_{1}(p) B(p)$.

Since there is a unit mass of varieties, a type- $i$ person's budget constraint can be 


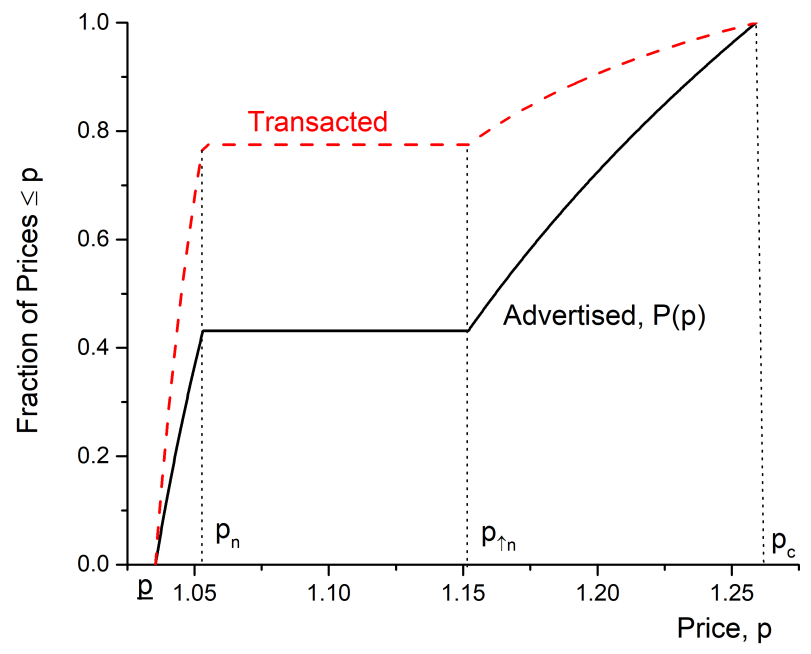

Figure 6: Cumulative distribution functions for both advertised prices, $P(p)$, and transacted prices when advertising is undirected. It is not profitable for a firm to price in the open interval $\left(p_{n}, p_{\uparrow n}\right)$. The advertised price distribution (first-order) stochastically dominates the transacted one, implying that at any price, $p$, the latter distribution has a greater fraction of prices $\leq p$. These are the actual price distributions that obtain in the calibrated equilibrium for the traditional advertising sector in hybrid model-Section 11 discusses the hybrid model's calibration.

written as

$$
a \int_{\underline{p}}^{p_{i}} p P_{1}(p) B(p) d p=\pi_{i} h_{i},
$$

where $h_{i}$ is hours worked and $p_{i}$ denotes the time price of the most expensive good the person will buy; i.e., $p_{i}=p_{n}$, for the non-college educated, and $p_{i}=p_{c}$, for the college educated. Equation (20) pins down $p_{n}$. To see this, set $i=n$ in (20) and perform the required integration, while using (17) and (18), to obtain

$$
a(\underline{p}-\gamma)\left\{\ln \left[\frac{p_{n}-\gamma}{\underline{p}-\gamma}\right]-\frac{\gamma}{p_{n}-\gamma}+\frac{\gamma}{\underline{p}-\gamma}\right\} / a=1-l_{n}
$$

This equation determines $p_{n}$. 


\section{The Consumer/Worker Problem}

A consumer/worker's optimization problem is to maximize (1) subject to (2) by the choice of $\{c(u)\}_{u=0}^{v}$ and $l$. This is done separately for each type $i$ of consumer, $i=n, c$. Focus on a generic type- $i$ worker and index the regular goods from the lowest to the highest priced so that $p(u)$ is increasing in $u$. Let $c_{i}$ index the most expensive generic good consumed by a type- $i$ individual, which has the price $p_{i}$. This also represents the person's overall consumption of generic goods because $c_{i}=\int_{0}^{c_{i}} c(u) d u$, as $c(u)=1$ for $u \in\left[0, c_{i}\right]$. Now, from the budget constraint (2) it's clear that $c_{i}$ can be written as a function of a person's productivity, $\pi_{i}$, and hours worked, $h_{i}$. So, write ${ }^{8}$

$$
c_{i}=C\left(h_{i}, \pi_{i}\right)
$$

with

$$
C_{1}\left(h_{i}, \pi_{i}\right)=\pi_{i} / p_{i}>0 \text { and } C_{2}\left(h_{i}, \pi_{i}\right)=h_{i} / p_{i}>0,
$$

In general consumers of a given type are buying different varieties of goods. This transpires because a consumer may not have gotten an ad for a given variety of goods or they got one but the price was too high. While this differs across consumers due to randomness, the statistical pattern is the same. A law of large number argument implies that each consumer faces the same the distribution of prices over the ads they received and therefore will be purchasing the same number of varieties even though the composition of these varieties is different. Thus, for a given type of consumer, the consumption/leisure problem takes the form of a representative agent.

Using this fact, the consumer/worker's maximization problem can be reformulated as ${ }^{9}$

$$
W_{i}=\max _{l_{i}}\left\{\theta \ln \left[C\left(1-l_{i}-\mathfrak{e}_{i}, \pi_{i}\right)\right]+\frac{(1-\theta)}{\rho} \ln \left[\kappa l_{i}^{\rho}+(1-\kappa) \mathfrak{m}^{\rho}\right]\right\}
$$

This problem has the same generic form for the traditional, digital, and hybrid advertising models. All that changes is the goods price, $p_{i}$, and the quantity of media-leisure goods, $\mathfrak{m}$. The generic first-order condition for the leisure of a type- $i$

\footnotetext{
${ }^{8}$ Note that $\int_{0}^{v} p(u) c(u) d u=\int_{0}^{c_{i}} p(u) c(u) d u=\pi_{i} h_{i}$, since $c_{i}$ is also the index of the last variety purchased [implying $c\left(c_{i}\right)=c_{i}$ ]. To compute $C_{1}\left(h_{i}, \pi_{i}\right)$, take the total differential of the above equation while using Leibniz's rule to get $p_{i} c_{i} d c_{i}=\pi_{i} d h_{i}$ so that $d c_{i} / d h_{i} \equiv C_{1}\left(h_{i}, \pi_{i}\right)=\pi_{i} / p_{i}$. A similar calculation gives the formula for $C_{2}\left(h_{i}, \pi_{i}\right)$.

${ }^{9}$ In the formula below, $\mathfrak{e}_{i}=0$ for $i=n$ and $\mathfrak{e}_{i}=\mathfrak{e}$ for $i=c$.
} 
person, or $l_{i}$, is:

$$
\underbrace{\frac{\theta}{c_{i}} \frac{\pi_{i}}{p_{i}}}_{\text {Marginal Cost of Leisure }}=\underbrace{(1-\theta) \frac{\kappa l_{i}^{\rho-1}}{\kappa l_{i}^{\rho}+(1-\kappa) \mathfrak{m}^{\rho}}}_{\text {Marginal BenEFit of Leisure }} \text {, for } i=n, c .
$$

The righthand side of this equation is the marginal benefit from an extra unit of leisure. It is increasing in the quantity of media-leisure goods, $\mathfrak{m}$, since $\rho<0$. The lefthand side is the marginal cost of leisure. An extra unit of leisure leads to a drop in income for a type- $i$ person. This causes a drop in regular consumption, $c_{i}$, of $\pi_{i} / p_{i}$, where $p_{i}$ is the price of the last regular good consumed. This is multiplied by the marginal utility of regular goods, $\theta / c_{i}$.

The upshot of this first-order condition is given by the proposition below. The proposition is important for both understanding the subsequent calibration procedure and the results on the model's workings.

Proposition 4. (Consumption/Leisure) An individual's consumption and leisure satisfy the following properties:

1. Leisure, $l_{i}$, is increasing in the number of media-leisure goods, $\mathfrak{m}$;

2. Regular consumption, $c_{i}$, is decreasing in the number of media-leisure goods, $\mathfrak{m}$, and is increasing in the level of skill, $\pi_{i}$;

3. Work effort, $h_{i}$, rises with the cost of an education, $\mathfrak{e}_{i}$.

Proof. See Appendix A.

The first point follows from the fact that an increase in the number of media goods, $\mathfrak{m}$, raises the marginal benefit of leisure, $l_{i}$, because the two goods are complements in the utility function (i.e., $\rho<0$ ). This property will be useful for identifying the quantities of free media-leisure goods in the calibration exercise for the hybrid model. Next, the rise in leisure, $l_{i}$, is connected with a drop in work effort, $h_{i}$, that reduces regular consumption, $c_{i}$. An increase in $\pi_{i}$ decreases the marginal cost of regular consumption in terms of forgone leisure. Hence, regular consumption rises. The third result transpires because an increase in $\mathfrak{e}_{i}$ raises the marginal cost of leisure for any given level of hours worked, $h_{i}$, as regular consumption, $c_{i}$, will be lower. This property is important because it implies that if an education is costly enough, then the college educated will work more than the non-college educated. This allows the 
calibrated hybrid model to explain the recent rise in the non-college's leisure relative to the college's.

Last, the overall consumption of generic goods by a type- $i$ person, $c_{i}$ for $i=n, c$, is given by

$$
c_{i}=a \int_{\underline{p}}^{p_{i}} B(p) P_{1}(p) d p[\mathrm{cf.}(20)]
$$

where again $P_{1}(p) B(p)$ represents the odds of a purchase at price $p$. Evaluating the integral at $i=n$ gives consumption for a non-college-educated person,

$$
\begin{aligned}
c_{n} & =a \int_{\underline{p}}^{p_{n}} \frac{\underline{p}-\gamma}{a(p-\gamma)^{2}} d p[\operatorname{using}(17) \text { and (18) }] \\
& =1-S\left(p_{n}\right) .
\end{aligned}
$$

The expression has an intuitive interpretation since $1-S\left(p_{n}\right)$ represents the odds for each variety of getting at least one advertised price less than or equal to $p_{n}$. Alternatively, when $i=c$ the formula yields a college-educated person's consumption,

$$
c_{c}=a\left[\int_{\underline{p}}^{p_{n}} \frac{\underline{p}-\gamma}{(p-\gamma)^{2}} d p+\frac{1}{1-\mathfrak{t}} \int_{p_{\uparrow n}}^{p_{c}} \frac{\underline{p}-\gamma}{(p-\gamma)^{2}} d p\right] / a=1-e^{-a} .
$$

Here, $1-e^{-a}=1-S\left(p_{c}\right)$ is the probability of receiving at least one ad per variety.

\section{Equilibrium}

The general equilibrium with traditional advertising is now characterized.

\section{Number of Varieties}

How many varieties, $v$, will be produced? Since there is free entry into the production of any variety of consumption goods all possible varieties are sold. If this wasn't the case, a producer could move into a variety where no one else is producing and earn supra-normal profits because of the lack of competition in advertised prices. Individuals will not consume all varieties, though. People won't receive ads for some varieties and even when they do get ads some varieties may be too expensive for non-college-educated consumers. 
Proposition 5. (Number of Varieties) All consumption goods in the feasible set $[0,1]$ will be produced; i.e., $v=1$.

Proof. See Appendix A.

\section{Supply of Free Media Goods}

It is immediate that the aggregate quantity of media goods provided, $\mathfrak{m}$, is given by

$$
\mathfrak{m}=v n_{t} \mathfrak{m}_{t}=n_{t} \mathfrak{m}_{t}
$$

To understand this equation, note that there are $n_{t}$ firms producing each variety. Each of these firms hire an ad agency running an advertising campaign that supplies $\mathfrak{m}_{t}$ media goods. By Proposition 5, there are $v=1$ varieties being supplied in economy.

\section{Labor Market Clearing}

In equilibrium the labor market must clear. The labor-market-clearing condition reads

$$
\begin{aligned}
& \gamma\left[\mathfrak{t} c_{n}+(1-\mathfrak{t}) c_{c}\right]+n_{t}\left[A\left(a_{t}\right)+\mathfrak{r}\right] \\
& =\mathfrak{t}\left[1-l_{n}\right]+(1-\mathfrak{t}) \pi_{c}\left[1-l_{c}-\mathfrak{e}\right] .
\end{aligned}
$$

The lefthand side is the demand for labor. The first term, $\gamma\left[\mathfrak{t} c_{n}+(1-\mathfrak{t}) c_{c}\right]$, is the demand for labor originating from the consumption of regular goods. The second term represents the labor used by the ad agencies that sell ads to the $n_{t}$ firms producing each variety, $n_{t}\left[A\left(a_{t}\right)+\mathfrak{r}\right]$. The righthand side is the supply of labor from non-college and college-educated workers. This condition can be thought of as tying down the number of entrants, $n_{t}$, into a variety of regular goods. (On this, note that the wage rate has been normalized to one so that the labor-market-clearing condition does not determine the wage rate as is often the case).

It's now time to take stock of things.

Definition of an Equilibrium An equilibrium for the economy is defined by a solution for advertising, $a_{t}$ and $a$, overall consumption, $c_{n}$ and $c_{c}$, the quantity of media goods consumed, $\mathfrak{m}$, labor supplies, $l_{n}$ and $l_{c}$, the number of firms producing each variety, $n_{t}$, and the prices of regular goods, $\underline{p}, p_{c}, p_{n}$, and $p_{\uparrow n}$, such that: 
1. Advertising is done in accordance with (9) and (10), which determines $a_{t}$, where $S(p)=1$. The solution depends on the values for $n_{t}$ and $p$. Given $a_{t}$, the price that an ad agency charges for an advertising campaign is specified by (3).

2. The minimum and maximum time prices for regular goods, $\underline{p}$ and $p_{c}$, are regulated by (11) and (13), taking as given a.

3. The highest time price paid by a non-college-educated person, $p_{n}$, is described by the pricing equation (21), assuming values for $a, l_{n}$, and $p$. The price for the college educated at the jump point, $p_{\uparrow n}$, is determined by (14) as a function of $p_{n}$.

4. The quantity of media goods enjoyed, $\mathfrak{m}$, is given by (27), where the solution for $\mathfrak{m}$ is dependent on the number of firms running advertising campaigns, $n_{t}$.

5. The solution to the consumer-worker's problem for $c_{i}$ and $l_{i}$ is governed by (24), (25), and (26) for $i=c, n$, given $p_{i}$ and $\mathfrak{m}$. These solutions take as given $a, \mathfrak{m}, \underline{p}, p_{n}, p_{\uparrow n}$, and $p_{c}$.

6. The labor market clears in accordance with (28), which gives the number of firms per variety, $n_{t}$, as a function of $a_{t}, c_{n}, c_{c}, l_{n}$, and $l_{c}$.

\section{Efficiency of the Traditional Advertising Equi- librium}

The competitive equilibrium is not efficient. This transpires for two reasons. First, ads offering to sell goods at high prices are being sent to non-college-educated consumers who can never afford to buy them. This is a social waste of resources. Second, when engaging in advertising, firms do not take into account how the introduction of free media goods benefits the consumer. So, there is an under provision of media goods. On both accounts, this is in contrast to the Butters (1977) model where the equilibrium is efficient.

The Pareto optima for the economy can be traced out by solving the following informationally-constrained planning problem, where $\xi>0$ is the relative planning 
weight that is being placed on non-college individuals:

$$
\begin{aligned}
\max _{c_{n}, c_{c}, a_{t}, n_{t}, l_{n}, l_{c}}\left\{\xi \mathfrak{t} \theta \ln c_{n}+\right. & \frac{\xi \mathfrak{t}(1-\theta)}{\rho} \ln \left[\kappa l_{n}^{\rho}+(1-\kappa)\left(n_{t} \mathfrak{m}_{t}\right)^{\rho}\right] \\
& \left.+(1-\mathfrak{t}) \theta \ln c_{c}+\frac{(1-\mathfrak{t})(1-\theta)}{\rho} \ln \left[\kappa l_{c}^{\rho}+(1-\kappa)\left(n_{t} \mathfrak{m}_{t}\right)^{\rho}\right]\right\},
\end{aligned}
$$

subject to an information constraint

$$
1-e^{-a_{t} n_{t}}-c_{c}=0
$$

and the resource constraint

$$
\mathfrak{t}\left[1-l_{n}\right]+(1-\mathfrak{t}) \pi_{c}\left[1-l_{c}-\mathfrak{e}\right]-\mathfrak{t} \gamma c_{n}-(1-\mathfrak{t}) \gamma c_{c}-n_{t}\left[A\left(a_{t}\right)+\mathfrak{r}\right]=0
$$

An interpretation of this problem is that the planner is giving non-college and collegeeducated people coupons in the amounts $c_{n}$ and $c_{c}$. Each coupon entitles a person to one good at the store they go to. The total amount of coupons handed out is constrained by the resource constraint (31). The advertisements give the locations of the stores that sell each variety. Without an ad the consumer will not know where to buy a variety. The odds of getting at least one ad for any particular variety are $1-e^{-a_{t} n_{t}}$. So, equation (30) states that consumption for the college educated is constrained by the ads they receive. This is the information constraint. Since $c_{c}>c_{m}$ the information constraint for the non-college educated will always be nonbinding when the one for the college educated holds.

The allocations from the informationally-constrained planning problem can be supported in a competitive equilibrium using a tax-cum-subsidy scheme. The excessive amount of advertising can be corrected by levying a fine on all advertising and providing a subsidy for consumers on all goods sold. Specifically, consumers require a proportional price reduction, $r$, in the amount

$$
r=1-\gamma / p_{n}
$$

and all advertising should be fined at the rate

$$
f=r p_{c}(1-\mathfrak{t}) e^{-a_{t} n_{t}} .
$$


The under provision of media goods can be rectified by providing a subsidy per media good in the amount $s$, where

$$
s=\mathfrak{t} \frac{(1-\kappa)}{\kappa}\left(\frac{\mathfrak{m}}{l_{n}}\right)^{\rho-1}+(1-\mathfrak{t}) \pi_{c} \frac{(1-\kappa)}{\kappa}\left(\frac{\mathfrak{m}}{l_{c}}\right)^{\rho-1} .
$$

The above policy should be financed by lump-sum taxation in line with

$$
\begin{aligned}
r a\left[\mathfrak{t} \int_{\underline{p}}^{p_{n}} p P_{1}(p) B(p) d p+(1-\mathfrak{t}) \int_{\underline{p}}^{p_{c}} p P_{1}(p) B(p) d p\right] & +s n_{t} \mathfrak{m}_{t} \\
& =\mathfrak{t} \tau_{n}+(1-\mathfrak{t}) \tau_{c}+f n_{t} a_{t}
\end{aligned}
$$

where $\tau_{n}$ and $\tau_{c}$ are the lump-sum taxes levied on the non-college and college educated. The way these taxes are raised affects the economy's income distribution.

Proposition 6. (Informationally-Constrained Efficiency when Advertising is Undirected) The solution to the informationally-constrained planning problem (29) can be supported as a competitive equilibrium with the tax-cum-subsidy scheme specified by (32), (33), and (34) that is financed by lump-sum taxation in accordance with (35).

Corollary. (Single agent economy) Suppose there is only one type of consumer/worker. Then only a subsidy on media goods is required.

Proof. This is a special case of the proof for the hybrid model presented in Appendix B.

Remark. Suppose that media goods don't enter preferences; i.e., $\kappa=1$. Then it is immediate from (34) that the subsidy on media goods could should be zero. Advertising will be excessive and should be fined in accordance with (33) and consumers will still require a price reduction as specified by (32).

The intuition for the above tax-cum-subsidy scheme is this. The college educated consume more varieties than the non-college educated. A certain amount of advertising is required to effect this. There is no need to do any extra advertising to support the non-college educated's consumption. So, the last variety sold to a noncollege-educated person should be priced at its marginal production cost implying that $(1-r) p_{n}=\gamma$, where $r$ is the required proportional price reduction. When determining how much advertising to do firms use the price $p$ instead of the subsidized 
price $(1-r) p$, where the latter reflects the value of the good to a consumer. Since $p>(1-r) p$ there is propensity toward too much advertising. This is corrected by fining advertising in general at the rate $f$.

Firms neglect the fact that media goods are valuable to consumers. Therefore, they under provide them. This is rectified by subsidizing media goods. The subsidy, $s$, is just an expenditure-weighted average of each group's marginal rate of substitution between leisure and media goods, as can be seen from (34). The marginal rates of substitution reflects how much an extra media good is worth to a person in terms of leisure. For a college-educated person a unit of leisure is worth more than for a non-college-educated person, as reflected by $\pi_{c}$.

Last, the solution to the planner's problem in a world with full information can be obtained by undertaking the maximization in (29) while dropping the information constraint (30). This can be supported as a competitive equilibrium where all goods are sold at the marginal cost so that $p=\gamma$.

\section{Digital Advertising}

The information age allows advertisers to collect vast amounts of information about consumers. Digital advertisers both collect and use information to target potential buyers. Suppose now that advertising can be directed based on income toward those consumers who will potentially buy the product, but that anyone can use the free media goods used to disseminate the ads. In such a setting there is no point sending an ad with a very high price to a consumer who can't afford to purchase the good at this price. So, directed advertising is more efficient than undirected advertising. It also is probably less annoying. To operationalize this idea the economy is split into two mutually exclusive spheres of economic activity, one for each consumer type. A firm can decide which group of consumers to sell to and at what price. These two spheres are only linked via the free-entry condition and the provision of free media goods. A capsule summary of the revised setup is now presented.

First, the number of firms per variety in each sphere is different, denoted by $n_{i}$, for $i=n, c$. Within each realm firms solve an advertising problem of the form (5). Since firms' profits must be the same across groups and prices due to the free-entry condition, all firms in the economy will do the same amount of digital advertising, $a_{d}$. The total amount of adverts within any variety is $a_{i}=n_{i} a_{d}$, for $i=n, c$. Second, 
there are separate resource constraints for each of the two spheres: ${ }^{10}$

$$
\gamma c_{n}+n_{n}\left[A\left(a_{d}\right)+\mathfrak{r}\right] / \mathbf{t}=1-l_{n}
$$

and

$$
\gamma c_{c}+n_{c}\left[A\left(a_{d}\right)+\mathfrak{r}\right] /(1-\mathbf{t})=\pi_{c}\left(1-l_{c}-\mathfrak{e}\right) .
$$

Third, the consumption of media goods, $\mathfrak{m}$, for both groups of individuals is given by

$$
\mathfrak{m}=\left(n_{n}+n_{c}\right) \mathfrak{m}_{d}
$$

\subsection{Pricing with Digital Advertising}

Each group of consumers faces their own advertised price distribution, $P_{i}(p)$ for $i=$ $n, c$. This occurs because they are targeted separately. As before, let the maximum prices for each group be represented by $p_{n}$ and $p_{c}$. For the non-college and college educated these prices respectively solve

$$
\left(p_{n}-\gamma\right) e^{-a_{n} / \mathfrak{t}}=\underline{p}-\gamma \text { and }\left(p_{c}-\gamma\right) e^{-a_{c} /(1-\mathfrak{t})}=\underline{p}-\gamma
$$

The minimum price, $\underline{p}$, is the same as in the equilibrium with undirected traditional advertising because, as was mentioned, this price depends only on technological considerations. It is now apparent that

Proposition 7. (Advertised Price Distributions when Advertising is Directed) The two advertised price distributions are

$$
P_{i}(p)=\operatorname{Pr}(\operatorname{PRICE} \leq p)= \begin{cases}\ln \{(p-\gamma) /(\underline{p}-\gamma)\} \mathbf{t} / a_{n}, & \text { for } p \in\left[\underline{p}, p_{n}\right], \quad i=n \\ \ln \{p-\gamma] /(\underline{p}-\gamma)\}(1-\mathbf{t}) / a_{c}, & \text { for } p \in\left[\underline{p}, p_{c}\right], \quad i=c\end{cases}
$$

Neither price distribution exhibits a flat portion associated with a jump in prices. Figure 7 illustrates the cumulative price distributions for both college and non-college consumers. Both price distributions start at the price $\underline{p}$, because this is technologically determined. Once again the distribution functions for advertised prices

\footnotetext{
${ }^{10}$ Actually, allowing for free mobility of labor across spheres, so there would be single resource constraint, doesn't change anything.
} 
(first-order) stochastically dominates their counterparts for transacted prices, because consumers buy at the lowest price they observe. The maximum price that the non-college educated will pay (denoted by $p_{n}$ ) is less than the one for the college educated $\left(p_{c}\right)$. Hence, the college-educated price distributions (first-order) stochastically dominate their analogues for the non-college educated. Directed advertising is more efficient than undirected advertising. because it is wasteful sending an advertised price to a non-college-educated consumer that is higher than the maximum they are willing to pay, $p_{n}$, in the event that they received no other advertisement.

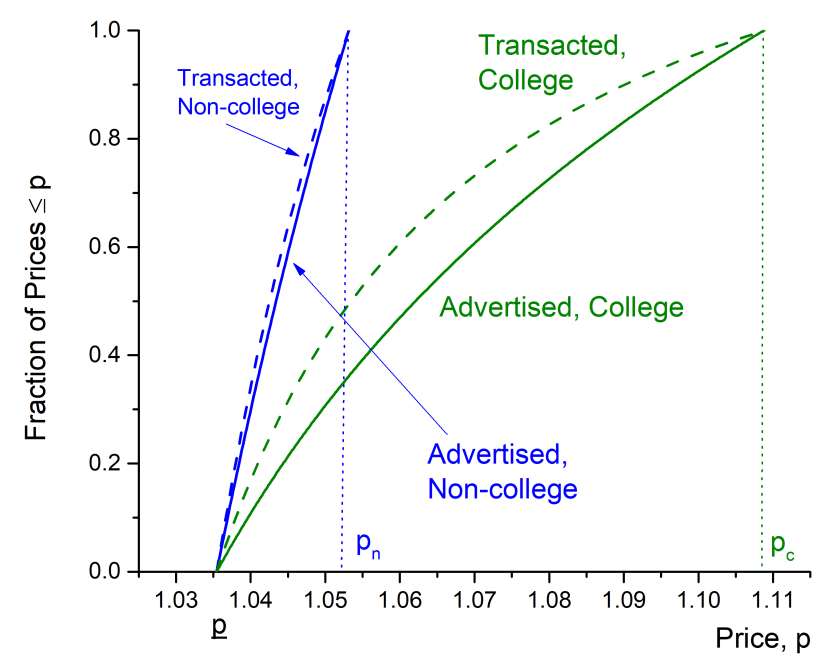

Figure 7: Cumulative distribution functions for both advertised prices, $P(p)$, and transacted prices when advertising is directed. When advertising can be directed, there will be separate price distributions for both the college and non-college populations. The college-educated distributions (first-order) stochastically dominate the non-college ones. Hence, at any given price, $p$, the non-college distributions have a larger share of prices $\leq p$. These are the actual price distributions that obtain in the calibrated equilibrium for the digital advertising sector in hybrid model-Section 11 discusses the hybrid model's calibration.

\subsection{Efficiency of the Digital Advertising Equilibrium}

The ability to target consumers by income eliminates wasteful advertising. So, the second-best tax-cum-subsidy public policy will not involve fining advertising or sub- 
sidizing prices. All that is needed is a subsidy for the fixed cost of providing media goods.

Proposition 8. (Informationally-Constrained Efficiency when Advertising is Directed) The second-best public policy involves subsidizing the fixed cost of providing media-leisure goods at the rate, s, specified by (34). This subsidy is financed by a lump-sum taxation scheme satisfying the government's budget constraint so that

$$
s\left(n_{n}+n_{c}\right) \mathfrak{m}_{d}=\mathfrak{t} \tau_{n}+(1-\mathfrak{t}) \tau_{c}
$$

Proof. This is a special case of the proof for the hybrid model presented in Appendix B.

\section{A Hybrid Model}

To incorporate both digital and traditional advertising, imagine an economy with consumers living in two separate advertising sectors: directed and undirected. Each sector has the same mix of non-college and college-educated workers. Individuals living in different sectors will face different distributions of advertised prices. In the sector with traditional advertising all consumers will face the same distribution of prices, as in Section 4. In the sector with digital advertising non-college-educated consumers will face a different distribution of prices than college-educated consumers due to targeting, in line with Section 9. So, the aggregate price distribution will be a mixture of three distributions. Let a subscript $n$ or $c$ denote whether a variable of interest refers either to the non-college or college segment of the population and a subscript $t$ or $d$ indicate whether the variable pertains to the traditional or digital advertising sector. At times there may be subscripts applying to both population types and sectors. The size of the traditional advertising sector is represented by $\#_{t}$ and hence the size of the digital sector is $1-\#_{t}$. In the calibration/simulation exercise $\#_{t}$ is allowed to change over time. The switch over time can be thought of as reflecting internet penetration or usage by consumers. For example, different demographic groups may enter the information age faster than others. Older people might favor watching TV while the young are more willing to surf the internet. ${ }^{11}$

\footnotetext{
${ }^{11}$ Research in progress using micro-level data, suggests a causal impact of internet adoption on digital advertising.
} 
Consumers in both sectors can enjoy all free media goods, $\mathfrak{m}$. Specifically,

$$
\mathfrak{m} \equiv n_{t} \mathfrak{m}_{t}+\left(n_{n d}+n_{c d}\right) \mathfrak{m}_{d}
$$

\subsection{Efficiency in the Hybrid Economy}

The second-best tax-cum-subsidy policy in the hybrid economy is just slightly more complicated than that for the traditional advertising economy. In particular, traditional advertising should be fined since it is provided excessively. Additionally, in the traditional advertising sector consumers should receive a price reduction. Once again there is a subsidy on providing media-leisure goods but now it reads

$$
\begin{aligned}
s=\#_{t}\left[\mathfrak{t} \frac{(1-\kappa)}{\kappa}\left(\frac{\mathfrak{m}}{l_{n t}}\right)^{\rho-1}\right. & \left.+(1-\mathfrak{t}) \frac{(1-\kappa)}{\kappa} \pi_{\mathfrak{c}}\left(\frac{\mathfrak{m}}{l_{c t}}\right)^{\rho-1}\right] \\
& +\left(1-\#_{t}\right)\left[\mathfrak{t} \frac{(1-\kappa)}{\kappa}\left(\frac{\mathfrak{m}}{l_{n d}}\right)^{\rho-1}+(1-\mathfrak{t}) \frac{(1-\kappa)}{\kappa} \pi_{\mathfrak{c}}\left(\frac{\mathfrak{m}}{l_{c d}}\right)^{\rho-1}\right]
\end{aligned}
$$

with $\mathfrak{m} \equiv n_{t} \mathfrak{m}_{t}+\left(n_{n c}+n_{c d}\right) \mathfrak{m}_{d}$

Proposition 9. (Informationally-Constrained Efficiency in the Hybrid Economy) The second-best public policy involves subsidizing the fixed cost of providing medialeisure goods in both sectors at the common rate, s, specified by (36). Traditional advertising is fined at the rate $f$ given by (33). Additionally, in the traditional advertising sector consumers receive a price reduction in the amount described by (32). This tax-cum-subsidy policy is financed by a lump-sum taxation scheme satisfying the goverment's budget constraint.

Proof. See Appendix B for details.

\section{Calibration}

The hybrid model is now calibrated to fit the U.S. data. Attach a superscript to a variable to denote a specified year. To simulate the model, values have to be assigned to the following 15 parameters: $\theta, \kappa, \rho, \mathfrak{m}_{\mathfrak{t}}, \mathfrak{m}_{d}, \gamma, \alpha, \phi, \mathfrak{r}, \pi_{c}, \mathfrak{e}, \#_{t}^{2003}, \#_{t}^{2010}, \#_{t}^{2018}$, and $\mathfrak{t}$. Most of the parameter values are unique to this study. Two parameters, $\gamma$ and $\phi$, are normalized to one; specifically $\gamma=\phi=1$. The non-college educated represent 
65 percent of the U.S. population, implying $\mathfrak{t}=0.65$. Given a set of parameter values, finding the solution to the model just involves solving a system of nonlinear equations as described in the definition of an equilibrium for the traditional advertising model, with the due modifications for the hybrid setting. Essentially, this involves the firstorder conditions from the consumers' and firms' maximization problems, the formulas for the directed and undirected price distributions, the supply of free media goods, and the labor-market-clearing conditions. A solution to the model exists for a wide range of parameter values and appears to be unique for each set of parameter values.

The calibration strategy is to pin down the remaining 12 parameter values by using a set of 12 data targets covering: the 2018 economy-wide markup; the 2018 average advertising-to-consumption ratio; the hike in the ratio of spending on digital versus traditional advertising between 2003 and 2018; the average 2018 college premium; and the step up in the average time spent on leisure by non-college- and college-educated individuals over 2003 to 2018. These parameters are selected to maximize the model's fit with respect to the data targets. While in general a parameter affects many data targets, it may have a bigger impact of some targets vis à vis others. The 12 data targets are now enumerated.

1. In United States the income of college graduates is 1.98 times that of the noncollege educated. Therefore, ideally the model should satisfy

$$
\operatorname{INCOME~RATIO}=1.98=\frac{\#_{t} \pi_{c}\left(1-l_{c t}-\mathfrak{e}\right)+\left(1-\#_{t}\right) \pi_{c}\left(1-l_{c d}-\mathfrak{e}\right)}{\#_{t}\left(1-l_{n t}\right)+\left(1-\#_{t}\right)\left(1-l_{n d}\right)} .
$$

This data target is key for identifying the productivity of the college educated, $\pi_{c}$.

2. A markup of 7 percent for the average transacted price over marginal production cost is chosen-this number is taken from Basu (2019). ${ }^{12}$ So, the data target for the model is

$$
\operatorname{MARKUP}=1.07=\#_{t} E_{t}[p] / \gamma+\left(1-\#_{t}\right) E_{d}[p] / \gamma
$$

where $E_{t}[p]$ and $E_{d}[p]$ are the average (or expected) prices in the traditional and digital advertising sectors. The expected price in the traditional sector is

\footnotetext{
${ }^{12}$ The size of price markups is controversial. The number used here is conservative for two reasons. First, it is unreasonable to believe that all of markups are due to advertising costs. Second, the larger is the price markup, the bigger is welfare gain from digital advertising for the college-educated. The welfare gain for the non-college educated remains roughly constant.
} 
given by

$$
E_{t}[p]=\frac{\int_{\underline{p}}^{p_{n t}} p B_{t}(p) P_{t 1}(p) d p+(1-\mathfrak{t}) \int_{p_{\uparrow n}}^{p_{c t}} p B_{t}(p) P_{t 1}(p) d p}{\int_{\underline{p}}^{p_{n t}} B_{t}(p) P_{t 1}(p) d p+(1-\mathfrak{t}) \int_{p_{\uparrow n}}^{p_{c t}} B_{t}(p) P_{t 1}(p) d p}
$$

where $P_{t 1}(p)$ is the density function for the advertised price distribution in the traditional sector. The expected price in the directed sector is a population weighted average of the prices paid by the non-college and college educated implying

$$
E_{d}[p]=\frac{\mathfrak{t} \int p B_{n d}(p) P_{n d 1}(p) d p+(1-\mathfrak{t}) \int_{\underline{p}}^{p_{c d}} p B_{c d}(p) P_{c d 1}(p) d p}{\mathfrak{t} \int_{\underline{p}}^{p_{n d}} B_{n d}(p) P_{n d 1}(p) d p+(1-\mathfrak{t}) \int_{\underline{p}}^{p_{c d}} B_{c d}(p) P_{c d 1}(p) d p}
$$

The markup is calculated using the transacted price distributions, shown in Figures 6 and 7 .

3. The advertising-to-consumption ratio was roughly 2 percent in 2018. Thus, ideally the following condition should hold for the model

$$
\begin{aligned}
\mathrm{A} 2 \mathrm{C} & =0.02=\frac{n_{t} A\left(a_{t}\right)}{\mathfrak{t}\left(1-l_{n t}\right)+(1-\mathfrak{t}) \pi_{c}\left(1-l_{c t}-e\right)} \\
& +\frac{n_{n d} A\left(a_{n d}\right)+n_{c d} A\left(a_{c d}\right)}{\mathfrak{t}\left(1-l_{n d}\right)+(1-\mathfrak{t}) \pi_{c}\left(1-l_{c d}-e\right)} .
\end{aligned}
$$

The two data targets (38) and (39) play an instrumental role in identifying the exponent on the advertising cost functions, $\alpha$, as well as the fixed cost of an advertising campaign, $\mathfrak{r}$. This transpires because they govern the amount of spending on advertising.

4. The relative size of the population living in the directed sector, $1-\#_{t}$, is calibrated so that it grows over time in accordance with the observed diffusion of digital advertising in United States. The ratio of spending on digital to traditional advertising rose from 0.02 percent in 2003 to 0.28 in 2018. Hence, the following 3 targets are imposed on the calibration exercise:

$$
\mathrm{D} 2 \mathrm{~T}=\frac{n_{n d} A\left(a_{n d}\right)+n_{c d} A\left(a_{c d}\right)}{n_{t} A\left(a_{t}\right)}= \begin{cases}0.02, & \text { for } 2003 \\ 0.07, & \text { for } 2010 \\ 0.28, & \text { for } 2018\end{cases}
$$


5. Last, the average values for leisure for college and non-college graduates for the years 2003, 2010, and 2018 are targeted. Leisure is defined as all time spent on entertainment, social activities, relaxing, active recreation, sleeping, eating, and personal care; this definition corresponds with Aguiar and Hurst (2007, Table III, measure 2). The trend in leisure is charted in Figure 8. Leisure for the non-college educated rose from 64.1 percent of time not working in 2003 to 65.4 in 2018. The increase for college graduates was from 60.7 to 61.6. In each year college graduates enjoyed less leisure than the non-college educated. Galbi (2001) has noted that, historically speaking, increases in discretionary time use are closely related to the waxing in time spent on media. So, the figure also tracks the gain in leisure since 2003 accounted for by the time consumed on media; namely, TV, radio, reading, movies, computers, and games. The model is calibrated to the 2003 levels of leisures and the subsequent gains in leisures linked with the increased time spent on media.

The data on leisure related to media goods, both over time and between the non-college and college educated, is used to infer the quantity of media goods. Because media goods and leisure are Edgeworth-Pareto complements, an increase in the supply of the media goods should lead to more time spent not working, ceteris paribus; recall Proposition 4. This type of strategy was introduced in Goolsbee and Klenow (2006) and followed by Brynjolfsson and Oh (2012). Things are more complicated here, though. The advent of digital advertising also affects the prices of consumer goods, which will have an impact on leisure as well. The average value of leisures for non-college and college graduates in the model should therefore match

$$
\text { leisure }_{n}=\#_{t} l_{n t}+\left(1-\#_{t}\right) l_{n d}= \begin{cases}0.6412, & \text { for } 2003 \\ 0.6501, & \text { for } 2010 \\ 0.6523, & \text { for } 2018\end{cases}
$$

and

$$
\text { leisure }_{c}=\#_{t} l_{c t}+\left(1-\#_{t}\right) l_{c d}= \begin{cases}0.6073, & \text { for } 2003 \\ 0.6130, & \text { for } 2010 \\ 0.6110, & \text { for } 2018\end{cases}
$$

This gives another 6 data targets for a total of 12 . This last set of data targets is important for determining the parameters that enter preferences, $\theta, \kappa, \rho, \mathfrak{m}_{\mathfrak{t}}, \mathfrak{m}_{d}$, as well as the cost of college, $\mathfrak{e}$, since these determine how much a person will work. Additionally, the observations that the college educated work more than the non-college educated identifies the cost of an education, $\mathfrak{e}$; again, recall 
Proposition 4.

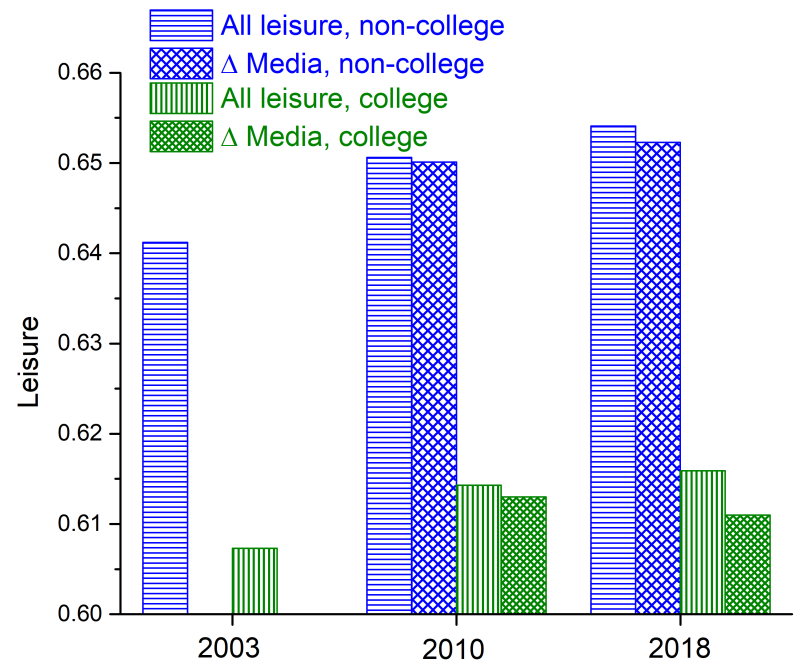

Figure 8: Leisure for the non-college and college educated. Also shown is the increase in leisure since 2003 comprised by shifts in time spent on media ( $\Delta$ Media). The bars for 2003 and the cross-hatched ones for 2010 and 2018 are used in the model's calibration. Source: American Time Use Survey.

Let data $a_{k}$ represent the $k$-th data target and $\operatorname{model}_{k}(\mathbf{p})$ be its analogue for the model as a function of the parameter vector $\mathbf{p} \equiv\left(\theta, \kappa, \rho, \mathfrak{m}_{t}, \mathfrak{m}_{d}, \alpha, \mathfrak{r}, \pi_{c}, \mathfrak{e}, \#^{2003}, \#^{2010}, \#^{2018}\right)$. Then, formally speaking, the parameter values in question solve

$$
\min _{\mathbf{p}} \sum_{k=1}^{12}\left[\operatorname{data}_{k}-\operatorname{model}_{k}(\mathbf{p})\right]^{2}
$$

The upshot from the calibration procedure is displayed in Tables 1 and 2 . 


\section{Calibrated Parameter Values}

\begin{tabular}{|c|c|c|}
\hline \multirow{2}{*}{\multicolumn{3}{|c|}{$\begin{array}{l}\text { Parameter Values } \\
\text { Consumers }\end{array}$}} \\
\hline & & \\
\hline$\theta=0.3496$ & Consumption weight & Data targets (41) and (42) \\
\hline$\kappa=0.0692$ & Weight on leisure, CES & Data targets (41) and (42) \\
\hline$\rho=-5.3867$ & Elasticity of substitution & Data targets (41) and (42) \\
\hline $\mathfrak{t}=0.65$ & Non-college educated, fraction & Data \\
\hline$\pi_{c}=2.3187$ & College-educated productivity & Data target (37) \\
\hline $\mathfrak{e}=0.0925$ & Cost of college & Data targets (41) and (42) \\
\hline Firms & & \\
\hline$\gamma=1$ & Marginal production cost & Normalization \\
\hline $\begin{array}{l}\text { Advertising } \\
\alpha=3.006\end{array}$ & Cost elasticity & Data targets \\
\hline $\mathfrak{r}=0.0026$ & Fixed advertising cost & Data targets (38) and (39) \\
\hline$\phi=1$ & Constant & Normalization \\
\hline $\mathfrak{m}_{t}=0.1517$ & Media goods, traditional & Data targets (41) and (42) \\
\hline $\mathfrak{m}_{d}=2.3272$ & Media goods, digital & Data targets (41) and (42) \\
\hline $\begin{array}{l}\text { Sector size } \\
\#_{t}^{03}=0.9668, \#_{t}^{10}=0.9089 \\
\#_{t}^{18}=0.7123\end{array}$ & Size traditional sector & Data targets (40) \\
\hline
\end{tabular}

Table 1: The parameter values that result from the calibration procedure for the hybrid economy. 
DAta TARgets

\begin{tabular}{lll}
\hline \hline Description & U.S. Data & Hybrid Model \\
\hline Income ratio & 1.98 & 1.98 \\
Markup, 2018 & 1.07 & 1.07 \\
Advertising/consumption, 1919-2019 & 0.02 & 0.02 \\
Digital/traditional advertising & & \\
$\quad 2018$ & 0.282 & 0.282 \\
2010 & 0.070 & 0.070 \\
2003 & 0.024 & 0.024 \\
Leisure & & \\
$\quad$ Non-college, 2018 & 0.6523 & 0.6525 \\
College, 2018 & 0.6110 & 0.6107 \\
$\quad$ Non-college, 2010 & 0.6501 & 0.6503 \\
College, 2010 & 0.6130 & 0.6126 \\
Non-college, 2003 & 0.6412 & 0.6408 \\
College, 2003 & 0.6073 & 0.6080 \\
\hline
\end{tabular}

Table 2: The data targets used in the calibration exercise and the corresponding numbers for the hybrid model.

\section{Welfare}

A person's welfare, $W_{i}$, reads

$$
W_{i}=\theta \ln \left(c_{i}\right)+\frac{(1-\theta)}{\rho} \ln \left[\kappa l_{i}^{\rho}+(1-\kappa) \mathfrak{m}^{\rho}\right], \text { for } i=n, c
$$

where $c_{i}, l_{i}$, and $\mathfrak{m}$ represent the allocations for (overall) consumption, leisure, and media goods under some particular scenario. From this it is clear that any change in welfare can be broken down into changes in $c_{i}, l_{i}$, and $\mathfrak{m}$. Now consider two different scenarios, $A$ and $B$. In order to move to regime $B$ a type- $i$ person living in regime $A$ would have to be compensated by boosting his regime- $A$ consumption by the factor

$$
\mathrm{EV}_{i}=e^{\left(W_{i}^{B}-W_{i}^{A}\right) / \theta}-1 .
$$


That is, $\mathrm{EV}_{i}$ measures a type- $i$ person's equivalent variation. ${ }^{13}$

\subsection{The Change in Welfare from 2003 to 2018}

Between 2003 and 2018, advertising became more efficient, due to the ability to target consumers better. ${ }^{14}$ This had three effects. First, consumers benefited from the introduction of new media goods. Second, leisure rose. Third, the reduction in hours was associated with a decline in consumption. By how much did welfare improve overall?

Table 3 shows the results. Average welfare increased for the non-college and college educated by 1.9 and 2.7 percent, in terms of consumption. ${ }^{15}$ For both groups of individuals, there is a significant increase in welfare due to the expansion of free media goods connected with digital advertising. The non-college educated realized a significant gain in welfare from their rise in leisure. This occurs because media goods and leisure are complements in utility; recall Proposition 4. The welfare gain from the increase in leisure is mostly offset by a decline in non-college educated consumption. The college educated enjoyed a smaller improvement in welfare from the rise in leisure. Their decline in consumption is negligible. The reduced work effort by the college-educated induced by an increase in media goods is counteracted by a reduction in prices at the high end stimulated by increased competition.

The shifts in advertised and transacted price distributions are shown in Figure 9. As Brynjolfsson and Smith (2000) observe, there is ample price dispersion in the data even for homogeneous goods. Qualitatively speaking, the model's predictions are consistent with the empirical findings of Brynjolfsson and Smith (2000) in many aspects: First, given the same good, prices on the internet are, on average lower than prices in conventional outlets; Second, transacted price dispersion is lower than

${ }^{13}$ In other words, $\mathrm{EV}_{i}$ solves the equation

$W_{i}^{B}$

$$
=\theta \ln \left[\left(1+\mathrm{EV}_{i}\right) c_{i}^{A}\right]+\frac{(1-\theta)}{\rho} \ln \left[\kappa\left(l_{i}^{A}\right)^{\rho}+(1-\kappa)\left(\mathfrak{m}^{A}\right)^{\rho}\right]
$$

${ }^{14}$ Allowing TFP to change in a balanced growth manner does not affect the results presented below in a material way, as was demonstrated in an earlier version of this research.

${ }^{15}$ For simplicity the aggregate change in welfare is measured from the perspectives of representative college- and non-college-educated consumers. Specifically, the change in welfare is based upon the average change in consumption, leisure, and media goods for the two groups. This does not materially change the welfare estimates, but eases comparisons across tables. 
advertised price dispersion; Third, transacted price dispersion is lower in internet channels than in conventional channels. ${ }^{16}$

This estimate of the improvement in welfare is not out of line with other work. Goolsbee and Klenow (2006) calculate that the internet was worth somewhere between 2 to 3 percent of income to the average consumer in 2005, but this could be as high as 27 percent depending on the preferred specification. Greenwood and Kopecky (2013) place the welfare gain from the introduction of personal computers at somewhere between 2 to 3 percent of GDP in 2004. Brynjolfsson and Oh (2012) find, using the Greenwood and Kopecky (2013) method, that the introduction of free media goods was worth about 5 percent of consumption in 2011.

The large boost in welfare generated by the free provision of media goods is not reflected in GDP. First, GDP is not the same as economic welfare. One might think that adding the implicit value of the free media goods to GDP would cure this problem. In particular, suppose that GDP is measured as $\mathrm{p}_{\mathfrak{c}} c+\mathrm{p}_{\mathfrak{m}} \mathfrak{m}$, where $c$ is aggregate consumption, $\mathrm{p}_{\mathrm{c}}$ is the price index for consumption, and $\mathrm{p}_{\mathfrak{m}}$ is the implicit price index for media goods. Standard reasoning suggests measuring this implicit price by the marginal rate of substitution between leisure and media goods. This differs across the rich and the poor, so take an expenditure-weighted average. It then turns out that $\mathrm{p}_{\mathfrak{m}}=s$, where $s$ is given by equation (34). Doing this would increase GDP by 8.1 percent in 2003, 1.7 percent in 2010, and 0.04 percent in 2018 . This seems counter intuitive because $\mathfrak{m}$ increased substantially over this time period, so how could media goods' contribution to GDP decline? As media goods increase their implicit price falls. So, once again, GDP is not the same as welfare. For example, electricity constitutes around 2 percent of expenditure yet Greenwood and Kopecky (2013) estimate it has a compensating variation of 92 percent with there existing no equivalent variation; i.e., it isn't possible to give a person today enough income to compensate them for living without electricity. Second, some researchers have suggested that advertising is an intangible investment and should be treated the same way as physical investment in the national income and product accounts. This boosts GDP. Advertising spending is deducted from firm's profits in the GDP

\footnotetext{
${ }^{16}$ Brynjolfsson and Smith (2000) mention that although models of information frictions have many predictions consistent with their findings, these models cannot explain all of the variance in prices. They argue that things such as awareness, branding, quality of service, and trust remain important sources of heterogeneity. Relatedly, Argente and Lee (2020) and Kaplan and SchulhoferWohl (2017) examine price distributions. They find that recent inflation hurt the poor more that the rich, hinting that this feature of the current model might be in data. More generally, Kaplan et al. (2019) compare the predictions of a price-posting model with the data. Additional research using micro-level data on different forms of advertising and price distributions is warranted before strong conclusions can be drawn. Models are useful for thinking about what to look for in the data.
} 


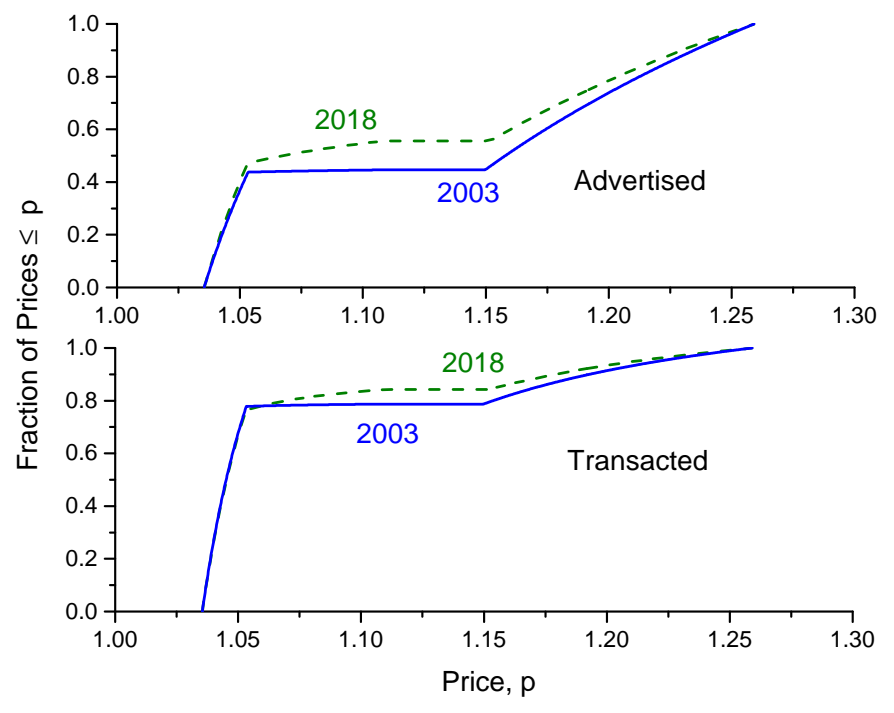

Figure 9: Shifts in the advertised and transacted price distributions between 2003 and 2018. The 2003 price distributions stochastically dominate their 2018 counterparts implying that a greater share of prices in 2003 were at the higher end. The advertised price distributions stochastically dominate their transacted analogues because consumers buy at the lowest prices they observe.

accounts unlike physical investment spending. ${ }^{17}$ Corrado, Hulten, and Sichel (2009) recommend counting (a portion of) advertising as an intangible investment in the GDP accounts-McGrattan and Prescott (2010) express a similar view. This would increase GDP by advertising's share of GDP, or around 2 percent over the last century. This adjustment would be constant over this time period and would not reflect the welfare gain from digital advertising-the ratio of advertising spending to

\footnotetext{
${ }^{17}$ For those not familiar with the issue, write the national income identity as

CONSUMPTION + INVESTMENT $+\ldots=$ LABOR INCOME + PROFITS + DEPRECIATION $+\ldots$.
}

Advertising is not currently counted as a component of investment. Suppose alternatively that advertising spending is added as a component of investment spending. On the lefthand side of the accounts, INVESTMENT would then increase by ADVERTISING. On the righthand side, ADVERTISING is no longer deducted from profits so that PROFITS and DEPRECIATION increase by ADVERTISING. That is, advertising expenditure is now capitalized instead of expensed. This retains a balance between the left- and right-hand sides of the national income accounts balance. GDP now increases by ADVERTISING. 
The InCRease in Welfare from 2003 to 2018, \% of Consumption

\begin{tabular}{lllll}
\hline \hline & EV & Consumption & Media Goods & Leisure \\
Non-college & 1.9 & -3.23 & 1.81 & 3.24 \\
College & 2.7 & 0.54 & 1.37 & 0.80 \\
\hline
\end{tabular}

Table 3: The welfare gains arising from the advent of digital advertising in the hybrid economy. These welfare gains are decomposed into the effects that digital advertising had on regular consumption, media goods provision, and leisure.

GDP has been stable.

It's dangerous to prognosticate about the future, but suppose, solely as a thought experiment, that digital advertising expands until 2040 at the same rate as between 2003 and 2018. Virtually all of the resulting welfare gains accrue to the college educated. From 2018 to 2040 the non-college educated would see their welfare climb by a measly 0.01 percent, while the college educated would enjoy a benefit of 1.45 percent. The cumulative welfare gains from 2003 on are shown in Figure 10. These additional welfare gains can be broken down. The free provision of media goods sees strong diminishing returns kick in after 2018. Even though $\mathfrak{m}$ rises strongly after 2018 consumers become satiated. This transpires because the utility function is very concave in media goods. The extra supply of free media goods increases welfare for both the non-college- and college-educated population by 0.01 percent for the 2018-2040 period. This is trivial compared with the gain between 2003 and 2018 . Most of the hike in welfare over this period derives from higher generic consumption resulting from more intense price competition strongly favoring the college educated; for the two parties, the numbers are 0 and 3.1 percent. Leisure changes little for both parties, rising slightly for the non-college educated and falling for the college educated. This leads to welfare gains of 0.05 and -0.1 percent. The loss in leisure for the college educated occurs because they realize a boost in their effective real wage due to a drop in prices at the upper end of the price distribution-a continuation of what was shown in Figure 9.

\subsection{Who pays?}

Who is implicitly paying for the provision of free media goods? Specifically, does consumption by the upper end of the population help the lower end by stimulating 

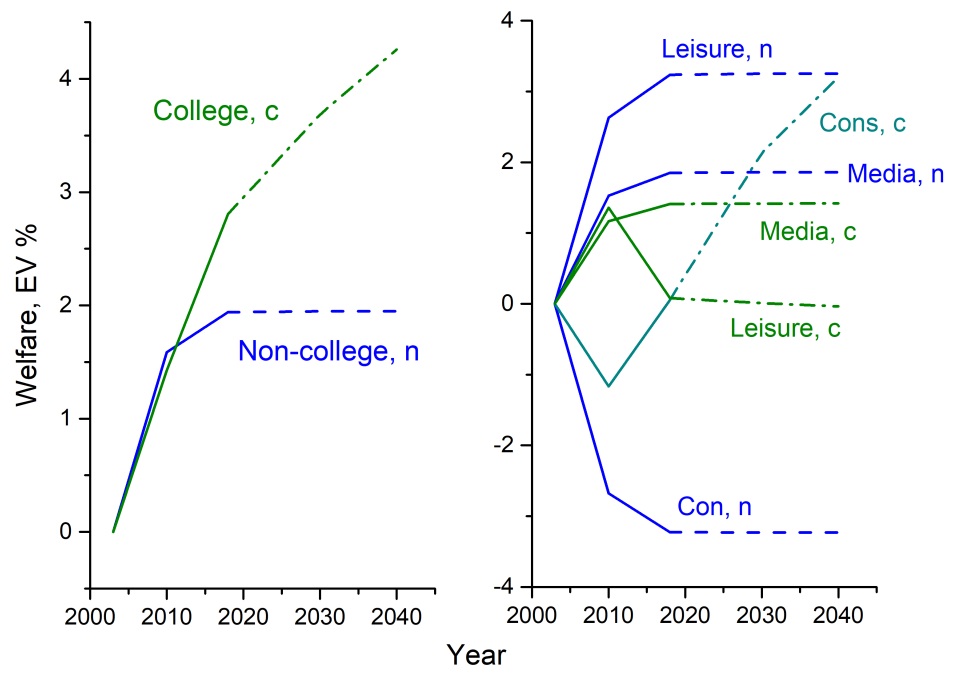

Figure 10: Cumulative welfare changes for the non-college and college educated population. The dashed and dot-dashed portions of the lines show the extrapolations from 2018 to 2040. Over this future period the college-educated gain a lot in welfare from generic consumption due to increased competition at the upper end of the price distribution. This is partially offset by a decline in welfare because of a reduction in leisure motivated by the rise in the real wage for the college educated.

the supply of free media goods? To begin with, the non-college share of advertising expenditure is given by

$$
\frac{\# t \mathfrak{t}\left(1-l_{n t}-\gamma c_{n t}\right)+\left(1-\#_{t}\right) \mathfrak{t}\left(1-l_{n d}-\gamma c_{n d}\right)}{\Delta},
$$

where

$$
\begin{aligned}
\Delta \equiv & \#_{t} \mathfrak{t}\left(1-l_{n t}-\gamma c_{n t}\right)+\left(1-\#_{t}\right) \mathfrak{t}\left(1-l_{n d}-\gamma c_{n d}\right) \\
& +\#_{t}(1-\mathfrak{t})\left(\pi_{c}\left(1-l_{c t}-e\right)-\gamma c_{c t}\right)+\left(1-\#_{t}\right)(1-\mathfrak{t})\left(\pi_{c}\left(1-l_{c d}-e\right)-\gamma c_{c d}\right) .
\end{aligned}
$$

The numerator is non-college income less the variable cost of their consumption. The calculation is done for both sectors and then summed. The numerator represents the slice of non-college income that is absorbed in advertising costs. The denominator is aggregate advertising expenditure. By this metric the non-college educated 


\begin{tabular}{lcc}
\multicolumn{2}{c}{ Share of } & Total Advertising Costs \\
\hline Type & Share, \% & Share/(Pop Share),\% \\
Non-college & 31.70 & 47.23 \\
College & 69.30 & 198.00 \\
\hline
\end{tabular}

Table 4: The fraction of the cost of free media good provision paid for by the noncollege- and college-educated populations in the hybrid economy.9.

pay 32 percent of the cost of advertising-see Table 4 . Note that the non-college educated represent $100 \times \mathfrak{t}=65$ percent of the population, so the percentage share per person is only 47 percent. The college-educated pay more than their share because they buy goods at higher prices where the markups are larger. Figure 11 plots the average advertising costs as fraction of a firm's revenue. When the price is higher the probability of making a sale, $S(p)$, is smaller. The odds of a sale drop faster than the price increases, so the cost of advertising is spread over a smaller amount of revenue.

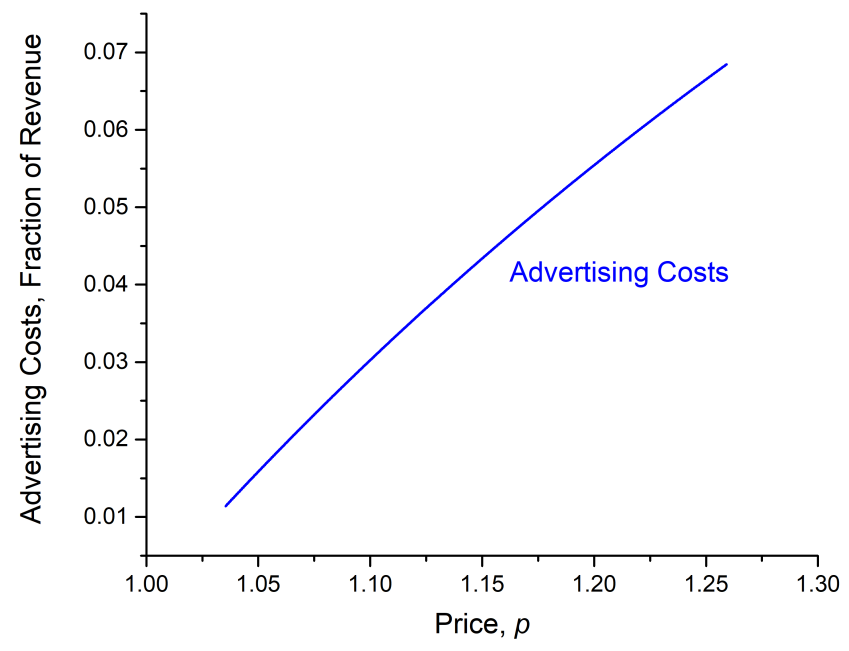

Figure 11: Advertising costs as a fraction of a firm's revenue rise with the price charged. 


\section{IMPLEMENTING THE EFFICIENT EQUILIBRIUM}

\begin{tabular}{|c|c|c|c|c|c|c|}
\hline EV, Non-college & EV, College & $r$ & $\overline{f f}$ & $s$ & lst $t_{n}$ & lst \\
\hline \multicolumn{7}{|c|}{ Informationally Constrained } \\
\hline $0.02 \%$ & $0.03 \%$ & $6.8 \%$ & $1.3 \%$ & $0.00 \%$ & $3.84 \%$ & $2.61 \%$ \\
\hline \multicolumn{7}{|c|}{ Full Information } \\
\hline$-3.28 \%$ & $15.71 \%$ & 0 & 0 & 0 & $6.98 \%$ & $-5.42 \%$ \\
\hline
\end{tabular}

Table 5: The tax-cum-subsidy policy needed to make the competitive equilibrium efficient and the welfare gains from doing so. The average lump-sum taxes paid by the non-college and college educated are denoted by $\mathbf{l s t}_{n}$ and $\mathbf{l s t}_{c}$.

\subsection{Public Policy}

By how much would welfare improve if the second-best tax-cum-subsidy scheme proposed in Section 8 was implemented? The upshot is presented in Table 5. Moving to the informationally-constrained efficient equilibrium has a small welfare gain, worth about 0.02 percent for the non-college educated and about 0.03 percent for the college educated. These are smaller than some of the magnitudes calculated in traditional welfare analyses, such as Rees's (1963) estimate of the welfare cost of labor unions, which he found to be 0.13 percent of GDP. They are bigger than Lucas's (1987) estimate of the welfare gains from eliminating business cycles.

Implementing the informationally-constrained efficient equilibrium would require a fairly large intervention in the economy. The purchase of consumption goods would have to be subsidized at 7 percent in order to align the marginal price paid by the non-college educated to its marginal production cost. Traditional advertising faces a small fine of 1.3 percent. Media goods provision is subsidized at an insignificant rate to compensate for the underprovision of media goods. Last, the lump-sum taxes required to implement the program would amount to 4.71 percent of labor income for the non-college educated and 3.23 percent for the college educated. While in the rarefied confines of the model such a policy is desirable, this is unlikely to be the case in the real world especially given the small welfare gain. The advertising equilibrium modeled is surprisingly close to being efficient in an informationallyconstrained economy.

The second-best informationally-constrained equilibrium is still some distance away from the first-best full-information equilibrium. To see this, the planner's problem in a full-information world is solved using the same utility weights as in the 
informationally-constrained problem, so as to keep things comparable. As can be seen, there is a big utility gain for college-educated consumers and a loss for noncollege-educated ones. In the full-information world, college-educated consumers benefit from a large drop in prices, which results in a big increase in their consumption. This effect is much smaller for non-college-educated consumers and is offset by a fall in the provision of free media goods. Fewer media goods are produced since there is no need for advertising now. Additionally, the poor must pay a lump-sum tax needed to finance the fixed costs of providing the media goods, while the rich actually receive a lump-sum subsidy. Both parties work more, and have less leisure, especially the non-college educated. This reinforces the message made in Table 4 that in the competitive equilibrium with advertising the college-educated are paying a disproportionate share of the cost of free media costs via the high markups on their consumption. It also shows that the information frictions regarding prices are fairly substantial.

Lest anyone worries, clearly resources could be redirected away from the collegeeducated toward the non-college educated that result in everyone being better off by a move to the first-best equilibrium; i.e., the full-information planning problem could be re-solved placing more weight on the non-college educated. But, there is no way of implementing the first-best equilibrium without a mechanism for costlessly getting price information to consumers.

\subsection{Annoying Ads}

Ads provide important facts for consumers; viz, prices, product specifications, and information about new goods. They can also be annoying. How much is an open question. In a randomized experiment of its 35 million customers the music streaming service Pandora found that as they increased the number of ads per hour less people tuned in and more people signed up for the $\$ 4.99$ per month ad-free version. An extra ad per hour led to a 2 percent drop in listeners and a 0.14 percent increase in paid subscribers. The increased revenue from the paid subscription service, how-

ever, did not make up for the loss in ad revenue. Only 30 percent of viewers for the video-on-demand service Hulu purchase the \$11.99-per-month no-commercials version versus the $\$ 5.99$ ad-supported plan-undirected TV and movie ads are probably the most disruptive form of advertising. In 2018 Hulu earned $\$ 1.5$ billion in ad revenue. Last, the opt-out rate on marketing emails is low, somewhere between 0.2 and 0.5 percent. Industry is endeavoring to find the sweet spot between the amount of advertising and fee for service. Consumers love free goods and services. The large networks built by Facebook, Google, and other tech giants allow for the rapid diffu- 
sion of the information contained in advertising. It's a profitable business model for these tech companies to use free goods as a vehicle to distribute advertising. The fact that consumers hate ads explains why digital advertising companies, such as Facebook and Google, don't just directly sell media goods to consumers instead of supplying them for free via advertising. A lot fewer consumers would view ads alone, if they weren't bundled with a product. Bundling free products with ads increases advertising companies profits. The fact that advertisers provide products for free makes it difficult for other companies to sell similar products.

How ads enter consumers' preferences is an open question. Suppose that they just detract from the enjoyment of media goods. Specifically, assume that they reduce the enjoyment of a media good by the gross factor $\xi$. This is effectively a renormalization of the constant term $\kappa$ on media goods. ${ }^{18}$ Therefore, nothing changes in the above analysis and the welfare gain from media goods can be thought of as having purged the nuisance of ads. Alternatively, perhaps consumers hate ads in their own right. In particular, subtract the disutility term $H$ (ads) from preferences, where ads are the advertisements received by a consumer. All of the positive analysis done here still goes through unaltered. The welfare analysis will change though. It would be difficult to parameterize the function $H$ without a lot of additional information. Additionally, the evidence suggests that consumers aren't willing to pay much for ad-free content. Could companies pay people (a negative price) to view ads? It might be hard to get the more affluent to view the ads for a small negative price. Becker and Murphy (1993) suggest that consumers could sell their "attention" to advertisers, but then just ignore the ads; therefore, there is a moral hazard problem with negative pricing.

\section{Closing}

An information-based model is developed where firms must advertise to sell goods. There are two modes of advertising; namely, traditional and digital. Advertising is executed via the provision of free media-leisure goods. Digital advertising is more efficient than traditional advertising because it can be directed better toward consumers who will actually buy the product. These media goods complement leisure in utility. Since there is randomness in the ads that consumers receive, firms set different prices for the exact same product. Hence, an equilibrium distribution of

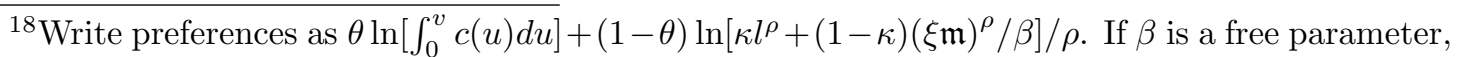
then setting $\beta=\xi^{\rho}$ shows that this is really a renormalization of the current setup. Without further information the two scenarios are observationally equivalent.
} 
prices emerges. The advertising equilibrium is not efficient. First, free media goods are underprovided. Second, traditional advertising is wasteful in the sense that ads are sent to consumers who can't afford to purchase the good at the posted price. A second-best tax-cum-subsidy policy that overcomes these inefficiencies is developed. Part of this policy involves subsidizing media goods provision and taxing advertising.

The developed model is matched up with some stylized facts from the U.S. data; in particular, the average price markup, the ratio of advertising expenses to consumption expenditure, the growth in the ratio of spending on digital advertising relative to traditional advertising, the college premium, and the rise in the time spent on leisure that was connected with media for both non-college- and college-educated people. Interestingly, the framework is consistent with the recent decrease in hours worked for the non-college educated relative to the college educated. The provision of free media goods via advertising is connected with a large increase in welfare. GDP is not a good measure of welfare when new goods are introduced into an economy. Adding an imputed value for the new media goods to GDP may not accurately reflect the gain in welfare. Additionally, counting advertising as component of investment in the GDP accounts may not capture the benefit of the digital advertising revolution. College-educated consumers pay a disproportionately large share of the cost of these media goods because they purchase products at higher prices. They may benefit from the introduction of digital advertising, however, due to the expansion of price competition at the upper end of the goods market relative to the lower end. The tax-cum-subsidy policy that overcomes these inefficiencies associated with advertising has a small impact on welfare, which is swamped by the welfare gain from the free provision of media goods. A comparison the first- and second-best equilibriums suggests that information frictions are significant.

Research in progress using micro data suggests that the advent of digital advertising has had a causal impact on the introduction of new varieties. Digital advertising is particularly favored by small firms. It may be the case that traditional advertising is used relatively more for general branding purposes, which are used more heavily by larger multiproduct firms.

\section{References}

[1] Aguiar, Mark and Erik Hurst. 2007. "Measuring Trends in Leisure: The Allocation of Time Over Five Decades." Quarterly Journal of Economics 122 (3): 969-1006. 
[2] Aguiar, Mark, Mark Bils, Kerwin Kofi Charles, and Erik Hurst. 2021. "Leisure Luxuries and the Labor Supply of Young Men." Journal of Political Economy, 129 (2): 337-382.

[3] Simon Anderson, Joel Waldfogel, and David Stromberg (eds). 2015. Handbook of Media Economics. Amsterdam: Elsevier.

[4] Argente, David and Munseob Lee. 2020. "Cost of Living Inequality During the Great Recession." Journal of the European Economic Association, 19 (2): 913952.

[5] Bagwell, Kyle. 2007. "The Economic Analysis of Advertising." In M. Armstrong and R. Porter (Eds), Handbook of Industrial Organization, Vol 3, Amsterdam: Elsevier B.V.: 1702-1844.

[6] Basu, Susanto. 2019. "Are Price-Cost Markups Rising in the United States? A Discussion of the Evidence." Journal of Economic Perspectives 33 (3): 3-22.

[7] Becker, Gary S. and Kevin M. Murphy. 1993. "A Simple Theory of Advertising as a Good or Bad." Quarterly Journal of Economics 108 (4): 941-964.

[8] Brynjolfsson, Erik and Joo Hee Oh. 2012. "The Attention Economy: Measuring the Value of Free Digital Services on the Internet." International Conference on Information Systems.

[9] Brynjolfsson, Erik, and Michael D. Smith. 2000. "Frictionless Commerce? A Comparison of Internet and Conventional Retailers." Management Science 46, (4): 563-585.

[10] Butters, Gerard R. 1977. "Equilibrium Distributions of Sales and Advertising Prices." Review of Economic Studies 44 (3): 465-491.

[11] Caillaud, Bernard, and Bruno Jullien. 2001. "Competing Cybermediaries." European Economic Review 45 (4-6): 797-808.

[12] Caillaud, Bernard, and Bruno Jullien. 2003. "Chicken \& Egg: Competition among Intermediation Service Providers." RAND Journal of Economics 34 (2): 309-328.

[13] Cavenaile, Laurent and Pau Roldan-Blance. 2021. "Advertising, Innovation, and Economic Growth." American Economic Journal: Macroeconomics 13 (3): 251303. 
[14] Cavenaile, Laurent, Murat Celick, Pau Roldan-Blanco, and Xu Tian. 2022. "Style over Substance? Advertising, Innovation, and Endogenous Market Structure." Unpublished paper, Unversity of Toronto.

[15] Cooley,Thomas F. and Edward C. Prescott. 1995. "Economic Growth and Business Cycles" Frontiers of Business Cycle Research, edited by Thomas F. Cooley, (Princeton, NJ: Princeton University Press): 1-38.

[16] Corrado, Carol, Charles Hulten, and Daniel Sichel. 2009. "Intangible Capital and U.S. Economic Growth." Review of Income and Wealth 55 (3): 661-685.

[17] Dinlersoz, Emin M. and Mehmet Yorukoglu. 2008. "Informative Advertising by Heterogeneous Firms." Information Economics and Policy 20 (2): 168-191.

[18] Dinlersoz, Emin M. and Mehmet Yorukoglu. 2012. "Information and Industry Dynamics." American Economic Review 102 (2): 884-913.

[19] Dinlersoz, Emin M., Nathan Goldschlag, Mehmet Yorukoglu, and Nikolas Zolas. 2021. "The Macroeconomics of Trademarks: Product Quality, Reallocation, and Welfare." Unpublished paper, Koc University.

[20] Fernald. John. 2014. "A Quarterly, Utilization-Adjusted Series on Total Factor Productivity." Working Paper 2012-19, Federal Reserve Bank of San Francisco.

[21] Galbi, Douglas A. 2001. "Communications Policy, Media Development, and Convergence." Unpublished Paper, Federal Communications Commission.

[22] Goldfarb, Avi. 2014. "What is Different About Online Advertising." Review of Industrial Organization 44 (2): 115-129.

[23] Goolsbee, Austin and Peter J. Klenow. 2006. "Valuing Consumer Products by the Time Spent Using Them: An Application to the Internet." American Economic Review 96 (2): 108-113.

[24] Gourio, Francois and Leena Rudanko. 2014. "Customer Capital." Review of Economic Studies 81 (3): 1102-1136.

[25] Greenwood, Jeremy and Karen A. Kopecky. 2013. "Measuring the Welfare Gain from Personal Computers." Economic Inquiry 51 (1): 336-347.

[26] Greenwood, Jeremy, Ananth Seshadri, and Mehmet Yorukoglu. 2005. "Engines of Liberation." Review of Economic Studies 72 (1): 109-133. 
[27] Greenwood, Jeremy and Guillaume Vandenbroucke. 2008. "Hours Worked (Long-Run Trends)." The New Palgrave Dictionary of Economics, v. 4, 2nd edition, edited by Lawrence E. Blume and Steven N. Durlauf, (New York, N.Y.: Palgrave Macmillan): 75-81.

[28] Kaplan, Greg, Guido Menzio, Leena Rudanko, and Nicholas Trachter. 2019. "Relative Price Dispersion: Evidence and Theory." American Economic Journal: Microeconomics. 11 (3): 68-124.

[29] Kaplan, Greg and Sam Schulhofer-Wohl. 2017. "Inflation at the Household Level." Journal of Monetary Economics 91 (C): 19-38.

[30] Kopecky, Karen A. 2011. "The Trend in Retirement." International Economic Review 52 (2): 287-316.

[31] Kopytov, Alexandr, Nikolai Roussanov, and Mathieu Taschereau-Dumouchel. 2021. "Cheap Thrills: the Price of Leisure and the Global Decline in Work Hours." Unpublished paper, University of Hong Kong.

[32] Lucas, Robert E., Jr. 1987. Models of Business Cycles. Oxford: Basil Blackwell Ltd.

[33] Marshall, Alfred. 1920. Industry and Trade: A Study of Industrial Technique and Business Organization; and of Their Influences on the Conditions of Various Classes and Nations. Third Edition. London: MacMillan and Co. Limited.

[34] McGrattan, Ellen R. and Edward C. Prescott. 2010. "Unmeasured Investment and the Puzzling U.S. Boom in the 1990s." American Economic Journal: Macroeconomics 2 (4): 88-123.

[35] Negishi, Takashi. 1960. "Welfare Economics and Existence of an Equilibrium for a Competitive Economy." Metroeconomica 12 (2-3): 92-97.

[36] Ozga, S. A. 1960. "Imperfect Markets Through Lack of Knowledge." Quarterly Journal of Economics 74 (1): 29-52.

[37] Perla, Jesse. 2019. "A Model of Product Awareness and Industry Life Cycles." Unpublished Paper, University of British Columbia.

[38] Rachel, Łukasz. 2020. "Leisure-Enhancing Technological Change." Unpublished Paper, London School of Economics. 
[39] Rees, Albert. 1963. "The Effects of Unions on Resource Allocation." The Journal of Law and Economics 6 (1): 69-78.

[40] Rochet, Jean-Charles, and Jean Tirole. 2003. "Platform Competition in Twosided Markets." Journal of the European Economic Association 1 (4): 990-1029.

[41] Stegeman, Mark. 1991. "Advertising in Competitive Markets." American Economic Review 81 (1): 210-223.

[42] Stigler, George J. 1961. "The Economics of Information." Journal of Political Economy 69 (3): 213-225.

[43] Telser, Lester G. 1964. "Advertising and Competition." Journal of Political Economy 72 (6): 537-562.

\section{A Appendix: Proofs for Propositions 1 to 4}

Proof. [Proof of Proposition 1 (Advertising)] Plugging the solution for $a_{t}$, given by (8), into the objective function (5) gives

$$
\Pi(p)=[(p-\gamma) S(p)]^{\alpha /(\alpha-1)} \Upsilon-\mathfrak{r}
$$

where

$$
\begin{aligned}
\Upsilon & \equiv \phi^{1 /(1-\alpha)}\left(\alpha^{1 /(1-\alpha)}-\alpha^{\alpha /(1-\alpha)}\right) \\
& =\left(\frac{1}{\phi}\right)^{1 /(\alpha-1)}\left(\frac{1}{\alpha}\right)^{\alpha /(\alpha-1)}(\alpha-1)>0 .
\end{aligned}
$$

Now, consider two firms charging two different prices, $p^{\prime}$ and $p^{\prime \prime}$, in the set $\mathcal{P}$. It must transpire that $\Pi\left(p^{\prime}\right)=\Pi\left(p^{\prime \prime}\right)$, which can only be true if $\left[\left(p^{\prime}-\gamma\right) S\left(p^{\prime}\right)\right]^{\alpha /(\alpha-1)}=$ $\left[\left(p^{\prime \prime}-\gamma\right) S\left(p^{\prime \prime}\right)\right]^{\alpha /(\alpha-1)}$. But then from (8), the solutions for $a_{t}$ must be the same.

Proof. [Proof of Proposition 2 (Pricing)] It's trivial to see from (11) and (13) that $p$ and $p_{c}$ are increasing in $\mathfrak{r}$ and $\gamma$. Last, $p_{c}$ falls with $(1-\mathfrak{t})$, as is immediate from (13).

Proof. [Proof of Proposition 3 (Price Distribution)] An exponentiation of equation 
(15) implies that

$$
P(p)=\frac{1}{a} \ln \left\{\frac{(p-\gamma)\left[\mathfrak{t} I_{n}(p)+(1-\mathfrak{t}) I_{c}(p)\right]}{\underline{p}-\gamma}\right\}
$$

The result follows by noting that $\mathfrak{t} I_{n}(p)+(1-\mathfrak{t}) I_{c}(p)=1$, when $p \in\left[\underline{p}, p_{n}\right]$, and $\mathfrak{t} I_{n}(p)+(1-\mathfrak{t}) I_{c}(p)=1-\mathfrak{t}$, when $p \in\left[p_{\uparrow n}, p_{c}\right]$. Last, since there are no firms that price in the range $\left[p_{n}, p_{\uparrow n}\right]$ the distribution function is flat over this interval. Equation (17) follows by taking the derivative of (16) with respect to $p$.

Proof. [Proof of Proposition 4 (Consumption/Leisure)] Focus on the first-order condition (24), which can be rewritten as ${ }^{19}$

$$
\underbrace{\frac{\theta}{c_{i}} \frac{\pi_{i}}{p_{i}}}_{\mathrm{MC}}=\underbrace{(1-\theta) \frac{\kappa}{\kappa l_{i}+(1-\kappa) \mathfrak{m}^{\rho} l_{i}^{1-\rho}}}_{\mathrm{MB}} .
$$

The above first-order condition can be represented diagrammatically, as shown in Figure 12. The lefthand side of (44) represents the marginal cost of leisure (MC). This is increasing in $l_{i}$, so the marginal cost curve is upward sloping. On this, note that both $c_{i}$ and $p_{i}$ are decreasing in $l_{i}$ by (22)-recall that prices are ordered from the lowest to the highest. The righthand side is the marginal benefit of leisure (MB). The righthand side is decreasing in $l_{i}$ so the marginal benefit curve is downward sloping.

1. To demonstrate the proposition's first point that leisure, $l_{i}$, will increase with the number of media goods, $\mathfrak{m}$, note that

$$
\frac{d \mathrm{MB}}{d \mathfrak{m}}=-\rho(1-\theta) \frac{\kappa(1-\kappa) l_{i}^{1-\rho}}{\left[\kappa l_{i}+(1-\kappa) \mathfrak{m}^{\rho} l_{i}^{1-\rho}\right]^{2}} \mathfrak{m}^{\rho-1}>0, \text { as } \rho<0 .
$$

${ }^{19}$ The righthand side is the marginal utility of leisure, $l_{i}$. Note that the marginal utility of media goods, $\mathfrak{m}$, has the symmetric form

$$
(1-\theta) \frac{(1-\kappa) \mathfrak{m}^{\rho-1}}{\kappa l_{i}^{\rho}+(1-\kappa) \mathfrak{m}^{\rho}}>0 .
$$

Taking the derivative of this with respect to $l_{i}$ also gives the cross partial given in (45). That is, if leisure is an Edgeworth-Pareto complement with media goods, then media goods are an EdgeworthPareto complement with leisure. 


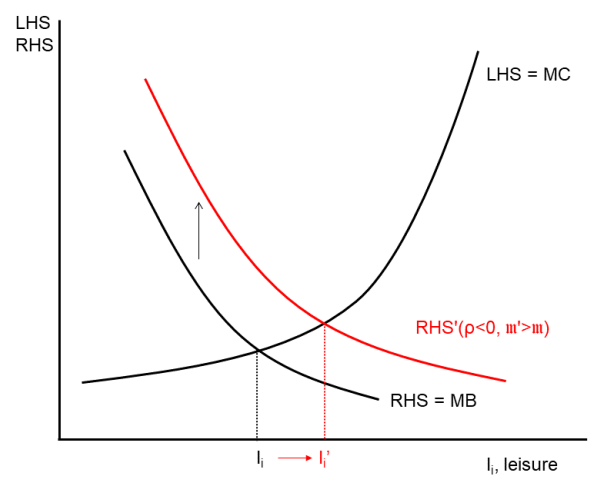

Figure 12: Leisure, $l_{i}$, is determined at the point where the marginal benefit and marginal cost curves intersect. The diagram shows what happens when the number of leisure goods increases from $\mathfrak{m}$ to $\mathfrak{m}^{\prime}$.

The marginal cost curve will stay in position, because it is not a function of $\mathfrak{m}$.

2. If leisure, $l_{i}$, increases with the free provision of media goods, then work effort, $h_{i}$, and income, $\pi_{i} h_{i}$, must fall. This leads to a drop in regular consumption, $c_{i}$. To show that regular consumption, $c_{i}$, is increasing in the level of skill, $\pi_{i}$, convert the first-order condition (44) for $l_{i}$ into one for $c_{i}$ by using the budget constraint (2). For a college-educated person this will read

$$
\frac{\theta}{c_{c}} \frac{\pi_{c}}{p_{c}}=(1-\theta) \frac{\kappa}{\kappa\left[1-\mathfrak{e}-\left(1 / \pi_{c}\right) \int_{0}^{c_{c}} p(u) d u\right]+(1-\kappa) \mathfrak{m}^{\rho}\left[1-\mathfrak{e}-\left(1 / \pi_{c}\right) \int_{0}^{c_{c}} p(u) d u\right]^{1-\rho}},
$$

where recall $c_{c}$ also is the index of the last variety purchased. (For the noncollege person just set $i=n$ and $\mathfrak{e}=0$.) The lefthand side is the marginal benefit of regular consumption, $c_{c}$, while the righthand side is its marginal cost. The marginal cost curve rises in $c_{c}$ while the marginal benefit curve declines in $c_{c}$. Here an increase in $\pi_{c}$ decreases the marginal cost of consumption, while it raises the marginal benefit. Hence, $c_{c}$ will increase.

3. Last, to establish that work effort for the college educated, $h_{c}=1-l_{c}-\mathfrak{e}$, is increasing in the cost of education, $\mathfrak{e}$, return to equation (44). Note that the marginal cost of leisure rises with $\mathfrak{e}$ because $c_{c}=C\left(h_{c}, \pi_{c}\right)$ will be smaller at 
any given level of $l_{c}$ by $(22)$ as $h_{c}=1-l_{c}-\mathfrak{e}$. The righthand side is unaffected by $\mathfrak{e}$.

Proof. [Proof of Proposition 5 (Number of Varieties)] Suppose that some consumption good $u$ is not produced. A producer could enter the variety, charging the maximum price, $p_{c}$, while advertising in the amount $a_{t}$. All high-type consumers receiving an ad would buy this good. The resulting level of supra-normal profits is

$$
\begin{aligned}
\left(p_{c}-\gamma\right)\left(a_{t}+a_{d}\right)(1-\mathfrak{t})- & A\left(a_{t}\right)-A\left(a_{d}\right)-\mathfrak{r}> \\
& \left(p_{c}-\gamma\right)\left(a_{t}+a_{d}\right) e^{-a}(1-\mathfrak{t})-A\left(a_{t}\right)-A\left(a_{d}\right)-\mathfrak{r}=0 .
\end{aligned}
$$

On the righthand side of the above equation $e^{-a}=S\left(p_{c}\right)$ is the odds that a firm selling another variety at price $p_{c}$ will make a sale. These positive profits violate the zero-profit condition.

\section{B Efficiency of Equilibrium in the Hybrid Model}

Following Negishi (1960), the question asked is whether or not there is a competitive equilibrium with a set of taxes and subsidies that shares the same allocations as an informationally-constrained planning problem. If so, then the competitive equilibrium with the proposed tax-cum-subsidy scheme is (informationally-constrained) Pareto optimal. The answer to this question is yes. Recall that in the hybrid model there are two sectors, one that uses traditional advertising and the other that uses digital advertising. Within the digital sector, advertising can be directed separately to non-college- and college-educated consumers. To conserve on notation, let the subscript $i=n, c$ denote whether or not a variable applies to an non-college- or college-educated person. Likewise, a subscript $j=t, d$ denotes whether the variable resides in the traditional or digital advertising sector. The proofs of Propositions 6 and 8 for the traditional and digital advertising economies are just special cases of Proposition 10 below for the hybrid economy.

\section{B.1 The Informationally-Constrained Planning Problem}

The planner's goal is to maximize a weighted average of individuals' utilities subject to the same informational frictions that exist in the competitive economy as well as 
the economy's resource constraint. The objective function for the informationallyconstrained planning problem for the hybrid economy can be expressed as

$$
\max _{c_{i j}, a_{t}, a_{i d}, n_{t}, n_{i d}, l_{i j}} \sum_{i=n, c j=t, d} \sum_{j}\left\{\xi_{i j} \mathfrak{t}_{i} \theta \ln c_{i j}+\frac{\xi_{i j} \mathfrak{t}_{i}(1-\theta)}{\rho} \ln \left[\kappa l_{i j}^{\rho}+(1-\kappa)\left(n_{t} \mathfrak{m}_{t}+\left(n_{n d}+n_{c d}\right) \mathfrak{m}_{d}\right)^{\rho}\right]\right\},
$$

where $\xi_{i, j}$ is the planning weights for a type $i=n, c$ consumer living in sector $j=t, d$, $\#_{j}$ is the size of sector $j$, and $\mathfrak{t}_{i}$ is the fraction of consumer/workers of type $i$. Note that $\mathfrak{t}_{\mathrm{n}}=\mathfrak{t}, \mathfrak{t}_{\mathrm{c}}=1-\mathfrak{t}$, and $\#_{c}=1-\#_{n}$. The maximization problem is subject to three information constraints

$$
\begin{gathered}
\#_{t} \mathfrak{t}_{c}\left(1-e^{-a_{t} n_{t} / \#_{t}}\right)-\#_{t} \mathfrak{t}_{c} c_{c t}=0, \\
\#_{d} \mathfrak{t}_{i}\left(1-e^{-a_{i d} n_{i d} /\left(\#_{d} \mathfrak{t}_{i}\right)}\right)-\#_{d} \mathfrak{t}_{i} c_{i d}=0, \text { for } i=n, c,
\end{gathered}
$$

and the single resource constraint

$$
\begin{aligned}
\sum_{j=t, d} \#_{j}\left\{\pi_{n} \mathfrak{t}_{\mathfrak{n}}\left(1-l_{n j}\right)\right. & \left.+\pi_{c} \mathfrak{t}_{\mathrm{c}}\left(1-l_{c j}-\mathfrak{e}\right)-\mathfrak{t}_{n} \gamma c_{n j}-\mathfrak{t}_{\mathrm{c}} \gamma c_{c j}\right\} \\
& -n_{t}\left[A\left(a_{t}\right)+\mathfrak{r}\right]-n_{n d}\left[A\left(a_{n d}\right)+\mathfrak{r}\right]-n_{c d}\left[A\left(a_{c d}\right)+\mathfrak{r}\right]=0
\end{aligned}
$$

where $\pi_{n} \equiv 1$. Attach the Lagrange multipliers $\omega_{c t}$ and $\omega_{i d}$, for $i=n, c$, to the information constraints and the one $\lambda$ to the resource constraint.

The 14 first-order conditions in compact form are:

$$
\begin{gathered}
\xi_{i j} \theta \frac{1}{c_{i j}}=\omega_{i j}+\lambda \gamma=\lambda\left(\omega_{i j} / \lambda+\gamma\right), \text { for } i=n, c \text { and } j=t, d, \text { with } \omega_{n t} \equiv 0 ; \\
\mathfrak{t}_{c} \omega_{c t} n_{t} e^{-a_{t} n_{t} / \#_{t}}=\lambda n_{t} A_{1}\left(a_{t}\right) ; \\
\omega_{i d} n_{i d} e^{-a_{i d} n_{i d} /\left(\#_{d} t_{i}\right)}=\lambda n_{i d} A_{1}\left(a_{i d}\right), \text { for } i=n, c \\
\sum_{i=n, c j=t, d} \sum_{j}\left[\xi_{i j} \mathfrak{t}_{i}(1-\theta) \frac{(1-\kappa) \mathfrak{m}^{\rho-1}}{\kappa l_{i j}^{\rho}+(1-\kappa) \mathfrak{m}^{\rho}}\right] \mathfrak{m}_{t}+\mathfrak{t}_{c} \omega_{t} a_{t} e^{-a_{t} n_{t} / \# t}=\lambda\left[A\left(a_{t}\right)+\mathfrak{r}\right] ;
\end{gathered}
$$




$$
\sum_{i=n, c j=t, d} \sum_{j}\left[\xi_{i j} \mathfrak{t}_{i}(1-\theta) \frac{(1-\kappa) \mathfrak{m}^{\rho-1}}{\kappa l_{i j}^{\rho}+(1-\kappa) \mathfrak{m}^{\rho}}\right] \mathfrak{m}_{d}+\omega_{i d} a_{i d} e^{-a_{i d} n_{i d} /\left(\#_{d} t_{i}\right)}=\lambda\left[A\left(a_{i d}\right)+\mathfrak{r}\right], \text { for } i=n, c
$$

$$
\xi_{i j}(1-\theta) \frac{\kappa l_{i j}^{\rho-1}}{\kappa l_{i j}^{\rho}+(1-\kappa) \mathfrak{m}^{\rho}}=\lambda \pi_{i}, \text { for } i=n, c, \text { and } j=t, d .
$$

In the above, $\mathfrak{m} \equiv n_{t} \mathfrak{m}_{t}+\left(n_{n d}+n_{c d}\right) \mathfrak{m}_{d}$.

\section{B.2 The Second-Best Competitive Equilibrium}

Before proceeding to proving that the competitive equilibrium with the proposed tax-cum-subsidy scheme is Pareto optimal, motivated by the forms of (54) and (55), conjecture that the common subsidy on each media-leisure good, $s$, is

$$
s=\sum_{i=n, c j=t, d} \#_{j}\left[\xi_{i j} \mathfrak{t}_{i}(1-\theta) \frac{(1-\kappa) \mathfrak{m}^{\rho-1}}{\kappa l_{i j}^{\rho}+(1-\kappa) \mathfrak{m}^{\rho}}\right] / \lambda .
$$

Using the first-order conditions for labor supplies (56), it can be seen that the righthand side of this expression collapses so that

$$
s=\sum_{i=n, c j=t, d} \sum_{j}\left[\mathfrak{t}_{i} \frac{(1-\kappa)}{\kappa} \pi_{\mathfrak{i}}\left(\frac{\mathfrak{m}}{l_{i j}}\right)^{\rho-1}\right] .
$$

Next, suppose that for the traditional advertising sector there is a proportional price reduction, $r_{t}$, on all sales in the amount

$$
r_{t}=1-\gamma / p_{n t},
$$

and a fine on advertising, $f_{t}$, given by

$$
f_{t}=r_{t} p_{c t} t_{\mathrm{c}} e^{-a_{t} n_{t} / \#_{t}} .
$$


The proportional price reduction implies that at the price $p_{n t}$ goods are sold in the traditional sector at marginal cost; i.e.,

$$
\left(1-r_{t}\right) p_{n t}=\gamma
$$

Let $\tau_{i j}$ be the lump-sum taxes needed to support this plan implying that

$$
\begin{aligned}
r_{t} \#{ }_{t} a_{t}\left[\mathfrak{t}_{\mathrm{n}} \int_{\underline{p}}^{p_{n t}} p P_{1}(p) B(p) d p+\right. & \left.\mathfrak{t}_{\mathrm{c}} \int_{\underline{p}}^{p_{c t}} p P_{1}(p) B(p) d p\right]+s \mathfrak{m} \\
& =f_{t} n_{t} a_{t}+\sum_{i=n, c} \sum_{j=t, d} \#_{j} \mathfrak{t}_{i} \tau_{i j} .
\end{aligned}
$$

In the above equation the functions $P_{1}(p)$ and $B(p)$ are specified by (17) and (19).

Proposition 10. (Informationally-Constrained Efficiency in the Hybrid Economy) The solution to the informationally-constrained planning problem can be supported as a competitive equilibrium with the tax-cum-subsidy scheme specified by (57), (58), and (59) that is financed with lump-sum taxation in accordance with (60).

Proof. The proof proceeds by a guess-and-verify technique. To this end, conjecture that

$$
\frac{\omega_{c t}}{\lambda}+\gamma=\left(1-r_{t}\right) p_{c t}
$$

an

$$
\frac{\omega_{i d}}{\lambda}+\gamma=p_{i d}, \text { for } i=n, c .
$$

To start with focus on the consumption/leisure allocations, while assuming that the solutions for advertising and the number of firms agree in both the competitive equilibrium and planning problems. Using (62) together with equations (51) and (56) gives the consumers' consumption/leisure first-order conditions in the competitive equilibrium for college-educated workers in the traditional and digital sectors and the non-college-educated workers in the digital sector. From the information constraints (48) and (49), $c_{c t}=1-e^{-a_{c t} n_{t} / \#_{t}}, c_{n d}=1-e^{-a_{n d} n_{n d} /\left(\#_{d} t_{n}\right)}$, and $c_{c d}=1-e^{-a_{c d} n_{c d} /\left(\#_{d} t_{c}\right)}$. This, along with the consumption/leisure first-order conditions, implies that the solutions for $l_{c t}, l_{n d}$, and $l_{c d}$, are the same in the competitive equilibrium and the planning problem. Analogously, using (61) in conjunction with equations (51) and (56) gives the first-order conditons for the college consumer in the traditional sector. Then, the resource constraint (50) implies the non-college person's consumption in 
the traditional sphere, $c_{n t}$, is the same as well. So, the allocations for $c_{i j}$ and $l_{i j}$ from the planning problem can be supported as a competitive equilibrium with the proposed subsidy-cum-tax policy.

Turn next to advertising. In the competitive equilibrium for the traditional sphere, $\underline{p}-\gamma=A_{1}\left(a_{t}\right)+f_{t}$. Add $f_{t}$ to both sides of equation (52) to obtain

$$
\mathfrak{t}_{\mathrm{c}}\left(\omega_{c t} / \lambda\right) e^{-a_{t} n_{t} / \#_{t}}+f_{t}=A_{1}\left(a_{t}\right)+f_{t}
$$

Using formula (59) for the fine on advertising, $f_{t}$, then gives

$$
\mathfrak{t}_{\mathrm{c}}\left(\omega_{c t} / \lambda+r_{t} p_{c t}\right) e^{-a_{t} n_{t} / \#_{t}}=A_{1}\left(a_{t}\right)+f_{t}
$$

Taking note of equation (58) leads to

$$
\mathfrak{t}_{\mathrm{c}}\left(p_{c t}-\gamma\right) e^{-a_{t} n_{t} / \#_{t}}=A_{1}\left(a_{t}\right)+f_{t}
$$

or

$$
\underline{p}-\gamma=A_{1}\left(a_{t}\right)+f_{t}
$$

because $\mathfrak{t}_{\mathrm{c}}\left(p_{c t}-\gamma\right) e^{-a_{t} n_{t} / \#_{t}}=\underline{p}-\gamma$. This is the first-order condition for $a_{t}$ in a competitive equilibrium. Therefore, the competitive solution for $a_{t}$, under the proposed subsidy-cum-tax policy, satisfies the planning problem. For the digital sector (where there is no fine) it is more immediate that

$$
\underline{p}-\gamma=A_{1}\left(a_{i d}\right), \text { for } i=n, c .
$$

Last, move on to the number of firms in the traditional sector. Multiply (52) by $a_{t} / \lambda$ to get

$$
\mathfrak{t}_{c}\left(\omega_{c t} / \lambda\right) n_{t} a_{t} e^{-a_{t} n_{t} / \#_{t}}=n_{t} a_{t} A_{1}\left(a_{t}\right)
$$

Rewrite (54) as

$$
a_{t} A_{1}\left(a_{t}\right)=A\left(a_{t}\right)+\mathfrak{r}-\sum_{i=n, c j=t, d} \sum_{j}\left[\xi_{i j} \mathfrak{t}_{i}(1-\theta) \frac{(1-\kappa) \mathfrak{m}^{\rho-1}}{\kappa l_{n t}^{\rho}+(1-\kappa) \mathfrak{m}^{\rho}}\right] \mathfrak{m}_{t} / \lambda
$$

Finally, multiplying the efficiency condition for traditional advertising (63) by $a_{t}$ and 
using the formula for $s$ [just above (57)] then gives

$$
(\underline{p}-\gamma) a_{t}=A\left(a_{t}\right)+\mathfrak{r}+f_{t} a_{t}-s \mathfrak{m}_{t}
$$

This is the zero-profit condition for a firm in the traditional sector when there is both a subsidy for media goods provision and a fine on advertising. This implies that the solution for $n_{t}$ from the planning problem will be shared by the competitive economy with the proposed subsidy-cum-tax policy. Similar calculations for the two digital spheres show that the zero-profit conditions hold there too.

Corollary. (Efficiency in the Traditional and Digital Advertising Economies) Propositions 6 and 8 hold.

Proof. These are just special cases of Proposition 10. For the subsidy, $s$, in the traditional advertising economy set $\#_{d}=0$ in (57) and for the subsidy in the digital advertising economy set $\#_{t}=0$.

\section{B.3 Recovering $r_{t}, f_{t}, s, \tau_{n t}, \tau_{c t}, \tau_{n d}$, and $\tau_{c d}$ from the Planning Problem}

The tax-cum-subsidy scheme that renders the competitive equilibrium efficient can be recovered from the solution to the planning problem. First, the subsidy on digital advertising, $s$, can be calculated from (57) using the planning problem allocations for $l_{n t}, l_{c t}, l_{n d}, l_{c d}$, and $\mathfrak{m}$.

Second, the proportional price reduction, $r_{t}$, and the fine on advertising, $f_{t}$, are immediate from (58) and (59), if the prices $p_{n t}$ and $p_{c t}$ are known. To recover these two prices, from the competitive equilibrium it transpires that

$$
1-S\left(p_{n t}\right)=1-\frac{p-\gamma}{p_{n t}-\gamma}=c_{n t}[\text { cf. equations (18) and (25)], }
$$

implying

$$
p_{n t}=\frac{\underline{p}-\gamma}{1-c_{n t}}+\gamma=\frac{e^{-a_{t} n_{t} / \#_{t}}(1-\mathfrak{t})\left(p_{c t}-\gamma\right)}{1-c_{n t}}+\gamma,
$$

where the term on the far right follows from substituting out for $p-\gamma$ using the equation just before (13). Next, by using the first-order condition (24) linked with the two consumer's problems in the traditional sector's competitive equilibrium with 
the proposed tax-cum-subsidy scheme, it transpires that

$$
p_{n t}=\Xi p_{c t}
$$

where

$$
\Xi \equiv\left(\frac{c_{c t}}{c_{n t}}\right) \frac{\kappa l_{n t}^{1-\rho}+(1-\kappa) \mathfrak{m}^{\rho} l_{n t}^{1-\rho}}{\pi_{c}\left[\kappa l_{c t}^{1-\rho}+(1-\kappa) \mathfrak{m}^{\rho} l_{c t}^{1-\rho}\right]} .
$$

Substituting the second formula for $p_{n t}$ into the first one for $p_{n t}$ then gives

$$
p_{c t}=\frac{\gamma(1-\Delta)}{\Xi-\Delta} \text { and } p_{n t}=\Xi \frac{\gamma(1-\Delta)}{\Xi-\Delta},
$$

where

$$
\Delta \equiv \frac{e^{-a_{t} n_{t} / \#_{t}}(1-\mathfrak{t})}{1-c_{n t}} .
$$

Since $a_{t}, c_{n t}, c_{c t}, \mathfrak{m}, l_{n t}$, and $l_{c t}$, are known from the planning problem so are $\Xi$ and $\Delta$.

Finally, by modifying the consumer/worker's budget constraint (20) to incorporate the tax-cum-subsidy policy, and then making use of the formulae for $P_{1}(p)$ and $B(p)$, the lump-sum taxes levied on the non-college- and college-educated in the traditional and digital sectors, $\tau_{n t}, \tau_{c t}, \tau_{n d}$, and $\tau_{c d}$, can be calculated to be

$$
\begin{gathered}
\tau_{n t}=1-l_{n t}-\left(1-r_{t}\right) a_{t}(\underline{p}-\gamma)\left\{\ln \left[\frac{p_{n t}-\gamma}{\underline{p}-\gamma}\right]-\frac{\gamma}{p_{n t}-\gamma}+\frac{\gamma}{\underline{p}-\gamma}\right\} / a_{t}, \\
\tau_{c t}=\pi_{c}\left[1-l_{c t}-\mathfrak{e}\right] \\
-\left(1-r_{t}\right) a_{t}(\underline{p}-\gamma)\left\{\ln \left[\frac{p_{n t}-\gamma}{\underline{p}-\gamma}\right]-\frac{\gamma}{p_{n t}-\gamma}+\frac{\gamma}{\underline{p}-\gamma}\right\} / a_{t} \\
-\frac{\left(1-r_{t}\right) a_{t}(\underline{p}-\gamma)}{1-\mathfrak{t}}\left\{\ln \left[\frac{p_{c t}-\gamma}{p_{\uparrow n t}-\gamma}\right]-\frac{\gamma}{\left(p_{n t}-\gamma\right)}+\frac{\gamma}{\left.p_{\uparrow n t}-\gamma\right)}\right\} / a_{t}, \\
\tau_{i d}=1-l_{i d}-a_{i d}(\underline{p}-\gamma)\left\{\ln \left[\frac{p_{i d}-\gamma}{\underline{p}-\gamma}\right]-\frac{\gamma}{p_{i d}-\gamma}+\frac{\gamma}{p-\gamma}\right\} / a_{i d}, \text { for } i=n, c,
\end{gathered}
$$

where

$$
p_{\uparrow n t}-\gamma=\frac{p_{n t}-\gamma}{1-\mathfrak{t}} .
$$




\section{Appendix: History}

Advertising has been around for eons. Babylonian merchants employed barkers who advertised their wares by shouting out. The Romans used signage outside of stores to sell wares; a bush signified a wine shop. Painted notices on the walls of bathhouses in Pompeii told of upcoming exhibitions. Marshall (1920, p. 271) noted that "A single prominent position in a great thoroughfare promotes the sale of many various things." After the arrival of the printing press came newspapers and then magazines. Benjamin Franklin published advertisements in his newspaper, the Pennsylvania Gazette. He is credited with publishing in 1741 the first magazine ad in the United States in the short-lived The General Magazine and Historical Chronicle, for all the British Plantations in America.

Advertising became an industry in the 19th century. N.W. Ayer \& Son was founded in Philadelphia in 1869. It sold complete advertising campaigns for businesses. It is credited with slogans such as "A diamond is forever" used by De Beers. A typical early 20th century magazine ad is displayed in Figure 13. Direct mail advertising started in 1872 with Aaron Montgomery Ward who launched a one page catalog, which was quickly followed by the Sears Catalog.

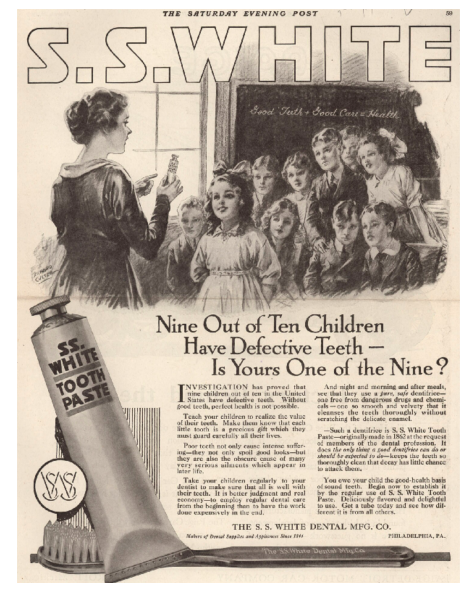

Figure 13: A 1919 toothpaste ad in the Saturday Evening Post magazine for S.S. White Dental Manufacturing Co. Source: Ad*Access, Duke Digital Repository.

Things changed rapidly in the 20th century with the advent of new technologies. Radio advertising started in the 1920s. In 1922 the first paid radio ad ran in New 
York City to promote the sale of apartments. It cost $\$ 50$ for 50 minutes of airtime. The first paid television ad was for Bulova watches. It was broadcast in 1941 before a baseball game between the Brooklyn Dodgers and Philadelphia Phillies. Television advertising expanded with the introduction of cable tv in the 1950s. MTV introduced music videos that were really just commercials for music artists. Additionally, channels were started that were devoted to advertising, such as HSN and QVC.

The information age began in the 1970s. A descendent of direct mail advertising is email marketing. This started in 1978 with an ad sent by Digital Equipment Corporation via the Arpanet to 400 DEC computer users. It didn't really take off until the 1990s when many people started to use the internet through outlets such as Microsoft's Hotmail that offered free email starting in 1996. Last, online advertising started in the 1990s.

The first search engine was Archie, created in 1990. Alan Emtage, its creator, developed an indexing technique that allowed Archie to catalogue "freely available or Public Domain documents, images, sounds and services on the network." Yahoo! Search was the first popular search engine, arriving in 1995. The next decade saw the rise of Google Search, which yielded better search results using an iterative algorithm that ranked web pages on the number of websites that linked to them and the ranking of these websites.

The first social media website is generally attributed to Six Degrees, founded in 1997. The name was based on the idea that people are linked to each other by six, or fewer, social connections. People could create profiles and "friend" each other. It had around 3.5 million users at its pinnacle. Things took off with the creation of MySpace in 2003. Between 2005 and 2008 it was the largest social media site in the world with over 100 million users per month. After 2008 Facebook dominated the social media world. Facebook had 2.5 billion monthly users in 2019. 